The University of Southern Mississippi

The Aquila Digital Community

Dissertations

Summer 8-2009

\title{
Sport as a Vehicle for Socialization and Maintenance of Cultural Identity: International Students Attending American Universities
}

James Taylor Allen

University of Southern Mississippi

Follow this and additional works at: https://aquila.usm.edu/dissertations

Part of the Kinesiology Commons, Sports Sciences Commons, and the Sports Studies Commons

\section{Recommended Citation}

Allen, James Taylor, "Sport as a Vehicle for Socialization and Maintenance of Cultural Identity: International Students Attending American Universities" (2009). Dissertations. 1050.

https://aquila.usm.edu/dissertations/1050

This Dissertation is brought to you for free and open access by The Aquila Digital Community. It has been accepted for inclusion in Dissertations by an authorized administrator of The Aquila Digital Community. For more information, please contact Joshua.Cromwell@usm.edu. 
The University of Southern Mississippi

SPORT AS A VEHICLE FOR SOCIALIZATION AND MAINTENANCE OF

CULTURAL IDENTITY:

INTERNATIONAL STUDENTS ATTENDING AMERICAN UNIVERSITIES

by

James Taylor Allen

A Dissertation

Submitted to the Graduate Studies Office of The University of Southern Mississippi in Partial Fulfillment of the Requirements

for the Degree of Doctor of Philosophy

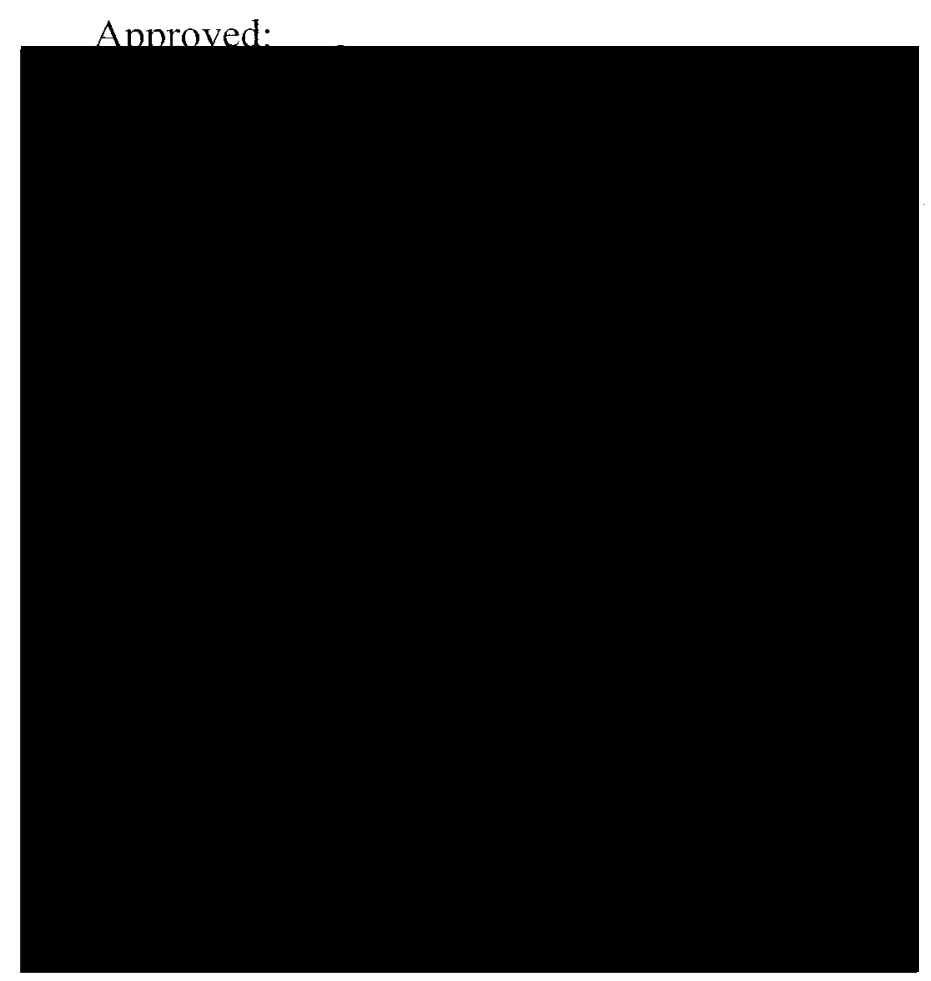

August 2009 
COPYRIGHT BY

JAMES TAYLOR ALLEN

2009 


\begin{abstract}
SPORT AS A VEHICLE FOR SOCIALIZATION AND MAINTENANCE OF CULTURAL IDENTITY:

INTERNATIONAL STUDENTS ATTENDING AMERICAN UNIVERSITIES

by

James Taylor Allen
\end{abstract}

\begin{abstract}
Dissertation
Submitted to the Graduate School of The University of Southern Mississippi in Partial Fulfillment of the Requirements for the Degree of Doctor of Philosophy
\end{abstract}




\begin{abstract}
SPORT AS A VEHICLE FOR SOCIALIZATION AND MAINTENANCE OF

CULTURAL IDENTITY:

INTERNATIONAL STUDENTS ATTENDING AMERICAN UNIVERSITIES

by James Taylor Allen
\end{abstract}

August 2009

Sport can be utilized by immigrants as a vehicle for maintaining cultural identity.

Conversely, sport participation provides immigrants with opportunities for adopting an entirely new culture. Previous research also suggests that sport provides individuals with opportunities for attaining social capital. While this can be a beneficial situation for some, sport is also promoting elitism and serving as a powerful mechanism for exclusion. Globalization has led large numbers of foreign nationals to seek educational opportunities in the United States. Due to the increase in the number of international students and the lack of empirical studies, the need to study their participation in sport is greater than ever. It is critical that sport managers ensure that these students are provided opportunities for socialization and cultural expression through sport. Thus far, there have been no holistic approaches that have examined international students with regards to socialization, cultural identity, and assimilation through sport. The present study is grounded in sociological theories that are widely recognized. For the purpose of the study, a scale measuring cultural identity and assimilation was developed based on literature review, exploratory factor analysis, and parallel analysis. The two factors retained; cultural maintenance and cultural assimilation through sport; were found to be valid and reliable 
measures of sport participation behavior among international students in the United States. A MANOVA test revealed that males scored significantly higher on the cultural maintenance through sport factor than females. The researchers detected a significant relationship between nationality and sport selection for participation. Practitioners involved in campus recreational sport are encouraged to utilize findings from the current study to enhance their programming efforts for international students. Furthermore, implications for sport managers are discussed with regards to promoting cultural diversity and inclusion. Additionally, the researchers examined sport spectatorship and media consumption behavior among international students. The researchers detected a significant relationship between nationality and sport selection for spectatorship. Also, males were significantly more likely to attend live sporting events with individuals from the same cultural background than females. Lastly, the international students' age and the length of time that they have lived in the US significantly impacted their sport media consumption. Sport programming and marketing strategies are discussed. 


\section{DEDICATION}

This dissertation is dedicated to my wife for providing love and understanding, my parents for providing support and encouragement, my grandparents for providing inspiration, my sister for providing camaraderie, and to all of my loyal friends. 


\section{ACKNOWLEDGEMENTS}

I would like to express my sincere gratitude to my committee members for their guidance, support, and encouragement throughout the process. You have all played an integral part in my academic, professional, and personal growth. To my Chair, Dr. Drane, you have made this dissertation possible. In my first semester as a doctoral student, you encouraged me to submit my research paper to the NASSM student paper competition. The review which I received helped me not only understand how to improve my study, but also how my study could become an important contribution to our body of knowledge. You then selected several elective courses for me to take which allowed me to develop my theoretical framework and methodology. Not only were you a mentor for me during the dissertation process, but you also provided guidance throughout my coursework and job search. I feel that you have been a dedicated advisor to me in every aspect of my career development and I recognize all of the sacrifices you have made in order to do what was best for my future. I am eternally thankful for your support.

To Dr. Phillips, you have always been supportive of my career development. It was you that I first reached out to about joining the doctoral program. From that point on, you have displayed your confidence in me and provided constant encouragement. You have been an excellent mentor to me by providing me with ideas, materials, and strategies for the classroom. I feel that our conversations have provided me with insight and fostered my dedication to sport management. To Dr. Byon, I feel incredibly fortunate to have been able to work with you. As soon as you arrived at Southern Miss you have been relentless in your pursuit of excellence. It would have been easy for you to focus on your 
own responsibilities during your first year as a professor, but instead, you dedicated countless hours to mentoring me. Your commitment and support mean so much to me.

To Dr. Hubble-Burchell, you have been an outstanding role model. Your professionalism and dedication to students and colleagues speaks volumes about your character. You have shown me not only what it takes become a quality faculty member, but also how to become a strong leader. To Dr. Mohn, I was not interested in statistics until I met you. Your passion and expertise made taking classes with you a wonderful experience. I have told countless people about your ability and always recommend that people work with you. I feel that Southern Miss is very fortunate to have you. Thank you for taking the time to serve on my dissertation committee. 


\section{TABLE OF CONTENTS}

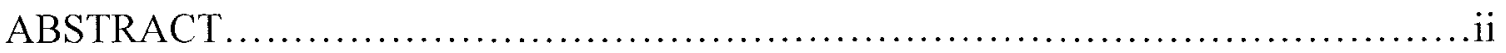

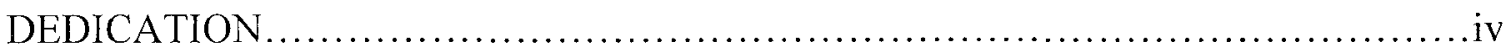

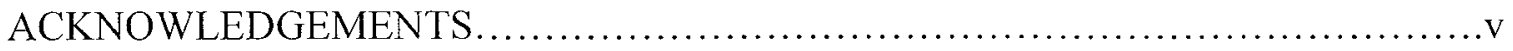

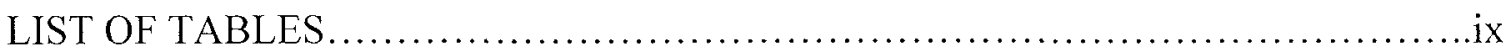

\section{CHAPTER}

I.

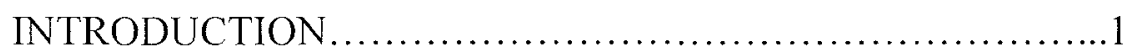

Purpose of Study

Research Hypotheses

Definition of Terms

Assumptions

Delimitations

Limitations

Justification of the Study

II. REVIEW OF RELATED LITERATURE $\ldots \ldots \ldots \ldots \ldots \ldots \ldots \ldots \ldots$

Theoretical Foundation

Sport and Immigrant Adaptation

Sport and Cultural Identity

Sport and Social Capital

International Students and Physical Activity

Instrumentation

Summary

III. METHODOLOGY

Research Design

Participants

Instrumentation

Procedures

References 
IV.

MANUSCRIPT ONE.

V.

MANUSCRIPT TWO

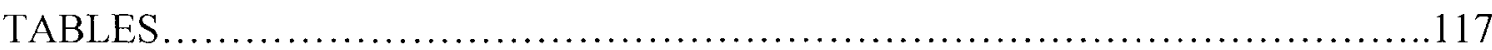

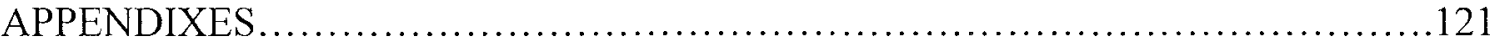

A. INSTITUTIONAL REVIEW BOARD APPROVAL ............121

B. INTERNATIONAL STUDENTS SPORT

PARTICIPATION AND CONSUMPTION SURVEY..........122

viii 


\section{LIST OF TABLES}

Table

1. Factor Loadings and Cronbach's Alpha.................................... 118

2. Sport Selection for Participation Based on Nationality $\ldots \ldots \ldots \ldots \ldots \ldots \ldots \ldots \ldots . \ldots 119$

3. Percentages for Sport Spectatorship Behaviors ........................... 120

4. Sport Selection for Spectatorship Based on Nationality $\ldots \ldots \ldots \ldots \ldots \ldots \ldots \ldots 121$ 


\section{CHAPTER I}

\section{INTRODUCTION}

Sport is one of the few social activities of human beings that can be seen in virtually every community and culture around the globe as a vehicle for bringing people together. For many, their sport participation is motivated by a desire to be a part of a cohesive group and internalize feelings of belonging. For others, there is a focus on the exercise and health benefits gained through sport participation. Some participants may only consider the health benefits when engaging in sport, but for many the experience is intrinsically connected to their identity and self-concept (Li \& Anderson, 2008; Weiss, 2001). Sport can be utilized as a way of maintaining one's cultural identity (Stodolska \& Alexandris, 2004).

On the other hand, sport can often be utilized to exclude individuals and promote elitism. Those who participate in the culturally dominant sport are awarded with more opportunities for socialization and have greater access to valuable social capital and power (Light \& Kirk, 2001). Individuals who are left on the outside looking in may lose out on opportunities for socialization, education, and even professional development (Majumdar, 2003). Prior research reveals that sport serves as a powerful mechanism for attaining social capital (Light \& Kirk; Stoddart, 2006). Once obtained, this social capital can be converted into economic capital (Light \& Kirk; Majumbar). Therefore, it is important to understand what connects certain groups of people to particular sports activities and what role these play in the reproduction of social and economic inequalities in a given society (Washington \& Karen, 2001). Globalization, which has often simply meant Westernization, fosters homogenous societies by marginalizing traditional cultures 
and ethnic communities (Hochschild, 2006). While sport can certainly be used to promote conformity and express western views, sport can at the same time serve as a vehicle for minority groups and foreign nationals to keep cultural ties strong (Burdsey, 2008;

Giossos, 2008; Lee, 2005).

\section{Purpose of Study}

Globalization has also led large numbers of foreign nationals to seek educational opportunities in the United States (Yoh, Yang, \& Gordon, 2008). College campuses across America enjoy a constant influx of international students. According to the Institute of International Education (2008), there were 623,805 international students enrolled at American universities for the 2007-2008 academic year (n.p.). For many of these students, obtaining a quality education and developing a lucrative career path is the primary motive for relocating to the United States (Li \& Stodolska, 2006). However, it is important that these students are provided opportunities for socialization, cultural expression and maintenance of physical health (Yoh, Yang, \& Gordon). Recreational sports can serve a multi-dimensional role for international students. For some, sport may simply be an activity to stay physically fit. Others may utilize sport to retain a sense of their homeland by engaging in a familiar recreational activity. Sport provides opportunities to socialize with other international students with the same or similar cultural background. Also, there may be some international students who view sport participation as an opportunity for assimilating into their new surroundings and new culture. Participating in public activities alongside individuals of the dominant culture facilitates assimilation for individuals of the subordinate culture (Gordon, 1964). Sport spectatorship, such as attending live events or watching events on television; also 
provides opportunities for socialization, maintenance of cultural identity, and assimilation.

While there have been numerous studies examining the role of sport in the lives' of immigrants (Harrolle \& Trail, 2007; Pons et al., 2001; Stodolska \& Alexandris, 2004), currently there is a gap in the body of research as only a few studies have focused specifically on international students. Research that has focused on international students has either concentrated exclusively on one nationality group or strictly examined frequency of participation (Lee, 2005; Li \& Stodolska, 2006; Yoh, Yang, \& Gordon, 2008). Thus, there have been no holistic approaches that have examined international students with regards to socialization, cultural identity, and assimilation through sport. The purpose of this study is to develop a valid and reliable instrument that can be utilized for understanding sport consumer behavior among international students attending American universities as it relates to socialization, cultural identity, and assimilation. For the purposes of this study, sport consumption includes both active participation and passive spectatorship.

\section{Research Hypotheses}

This study was guided by the following research hypotheses:

$\mathrm{H}_{1}$ : The international student's nationality will impact their behavior with regards to participating with individuals from the same cultural background or with individuals from a different cultural background.

$\mathrm{H}_{2}$ : The international student's nationality will impact their intention to utilize sport as a vehicle for assimilating into their new cultural environment or as a vehicle for maintaining the cultural identity associated with their heritage. 
$\mathrm{H}_{3}$ : There will be a significant relationship between nationality and the particular sport(s) that international students most frequently participate in and consume as spectators.

$\mathrm{H}_{4}$ : The length of time that international students have been living in the United States will significantly impact the frequency of their participation.

$\mathrm{H}_{5}$ : The length of time spent living in the United States will significantly impact the international student's sport participation behavior with regards to utilizing sport as a vehicle for assimilating into a new culture or as a vehicle for maintaining the cultural identity associated with their heritage.

\section{Definition of Terms}

Assimilation: the process by which an individual voluntarily adopts aspects of the dominant culture. In the case of immigrants and cultural assimilation, we are referring to the adoption of language, cultural values and norms, and other public behavior that may enhance transition into their new environment.

Cultural identity: the self-image of a cultural group or the self-image of an individual that has been influenced by their belonging to a particular cultural group.

Culture: refers to the distinct manner in which human beings living in different parts of the world creatively express and represent their life experience.

Recreational sport: organized or casual competitive physical activities and excludes NCAA and professional sport participation.

Social capital: refers to the aggregate of the actual or potential resources which are linked to possession of a durable network of more or less institutionalized relationships of mutual acquaintance and recognition (Bourdieu, 1977). 
Socialization: refers to individuals interacting with one another in order to adopt behavior patterns and norms necessary for being a member of society.

Sport spectatorship: passive sport participation which involves observing other individuals as they actively participate in sport. This includes attending live sport events, watching televised sporting events, listening to sporting events on the radio, and viewing footage from sporting events via the internet.

Assumptions

The assumptions of this study were the following:

1. All subjects will give accurate and honest responses to all information asked of them.

2. All subjects will be international students attending one of the four universities participating in the study.

\section{Delimitations}

The delimitations of this study were the following:

1. The study was delimited to current international students from four comprehensive universities in the United States, and does not include every international student in the United States.

2. The subjects voluntarily self-selected to participate in the study by responding to an e-mail message sent to them through their university's international studies department.

\section{Limitations}

1. The study was limited to behaviors relevant to recreational sport participation and sport spectatorship measured in the instrument. It is quite possible that variables not 
included in the instrument would help to explain sport consumer behavior among international students.

2. The international students' recall of their active participation and spectator behavior was not controllable.

\section{Justification of the Study}

Sport can be utilized by international students in a variety of ways. For some, sport participation and spectatorship provides opportunities for social networking. These networking opportunities may allow the international students to assimilate into his/her new cultural environment. Others may utilize their sport participation and spectatorship to maintain or strengthen ties to their ethnic group. Sport participation and spectatorship also provides the international student with opportunities to gain knowledge about other cultures and helps build trust and understanding between diverse ethnic groups.

Numerous studies have examined the role of sport in the lives of immigrants (Harrolle \& Trail, 2007; Pons et al., 2001; Stodolska \& Alexandris, 2004). Harrolle and Trail and Pons et. al developed instruments for assessing the relationship between ethnic identity and sport fan behavior amongst immigrants. Stodolska and Alexandris conducted a qualitative study that examined the sport experiences and assimilation paths of Korean and Polish immigrants in Illinois. However, very few empirical studies have focused specifically on international students attending American universities. Studies that have focused on international students and sport have either concentrated exclusively on one nationality group (Chinese) or strictly examined frequency of participation (Li \& Stodolska, 2006; Yoh, Yang, \& Gordon, 2008). Due to the increase in the number of international students and the lack of empirical studies, the need to study their 
participation in sport is greater than ever (Yoh, Yang, \& Gordon). The present study focuses on the entire international student population, regardless of nationality; and seeks to gain a better understanding of the relationship between sport and socialization, cultural identity, assimilation, and sport consumption behavior. Results from this study will enable American universities to better understand the unique characteristics of the international students and their sport participation. Furthermore, this study will obtain important information for practitioners involved in the programming of recreational sport. Acquiring a better understanding of the sport participation patterns and consumer behavior characteristics of international students enables practitioners to more effectively target this audience. Sport programming and promotional efforts can be tailored to meet the needs of this growing segment of the U.S. population. 


\section{CHAPTER II}

\section{REVIEW OF RELATED LITERATURE}

The purpose of this study was to understand sport participation behavior among international students attending American universities as it relates to socialization, cultural identity, and assimilation. The secondary purpose of this study was to examine sport spectatorship patterns and consumer behavior of international students as these also play a vital role in the socialization, maintenance of cultural identity, and assimilation processes. The following is a presentation of relevant literature pertaining to this study and is divided into five categories: (1) Theoretical Foundation, (2) Sport and Immigrant Adaptation, (3) Sport and Cultural Identity, (4) Sport and Social Capital, (5) International Students and Physical Activity, and (6) Instrumentation.

\section{Theoretical Foundation}

What happens to society when cultural practices, religious beliefs and political ideologies increase in diversity? There must remain some point of attachment that facilitates group solidarity. Emile Durkheim is considered one of the founding fathers of sociology and an early proponent of solidarism. Durkheim (1972) insisted that society was greater than the sum of its parts and coined the term collective consciousness. He describes individual's shared beliefs, or the collective consciousness, as a vehicle for maintaining social solidarity. Social solidarity is essential for society to function. With out this binding of individuals into a cohesive social unit, society would disintegrate; thus resulting in chaos (Durkheim). While typically we think of organized religion or the educational systems as facilitators for group attachment, certainly sport facilitates this process as well. International students are able to internalize feelings of belonging and 
solidarity through participating in sport with others that share their cultural background, thus facilitating the transition into their new society.

Some researchers examining sport have found a symbolic interactionist frame and identity theory to be useful for their work (Weiss, 2001). This frame and theory emphasizes conception of self and describes identity as internalized expectations resulting from roles that are entrenched in organized networks of social interaction (Allan, 2007). Social structures are viewed as facilitators for bringing people into networks or constraints in keeping them out. Identity theory, rooted in the work of George Herbert Mead, is interested in the social basis of meaning, self, and action (Allan). The process of the individual interacting with others in order to create an identity is referred to as identity negotiation. The purpose of identity negotiation is to develop a set of behaviors that will reinforce the identity of the individual (Mead, 1934). For example, participants in sport are able to display their dexterity, strength, knowledge, intelligence, courage or self-control; qualities that are expected in their social environment (Weiss).

Notes from Mead's influential lectures at the University of Chicago were compiled by students and synthesized into the book Mind, Self, \& Society. Mead takes into consideration both behavioral psychology and societal factors while attempting to explain the gestures and forms of communication displayed by the individual. Each individual determines his behavior in terms of what other individuals are doing. Gestures are meaningful symbols and indicate upcoming actions. The self arises from these social experiences and human beings initially develop their understanding of the world through "play" (Mead, 1934). "Play" refers to a child's development where adult roles are 
observed and then mimicked. As the child progresses, he participates in the "game", which incorporates organized rules that require specific responses. During the "game" stage the individual must have the attitude of all the others involved in the activity. Mead uses an example of a person playing baseball where the individual's actions are determined by his assumptions of the others who are playing the game. What the individual does "is controlled by his being everyone else on that team, at least in so far as those attitudes impact his own response" (Mead, p. 154).

The organization of these attitudes and actions of the participants provides the individual with his unity of self which Mead refers to as "the generalized other" (Mead, 1934, p. 154). Mead explains, "the attitude of the generalized other is the attitude of the entire community" (Mead, p. 154). In the baseball example, the team is the "generalized other". Mead also refers to the accumulated understanding of the "generalized other" (opinions, norms, social response patterns) as the "me". With regards to teamwork the individual identifies with the group, but is doing something different from the others, even though what the others do is ultimately going to determine what he does. Mead indicates that through the process of teamwork, there can be a fusion of the "I" and "me" which leads to an intense emotional experience. The "I" represents the personal, selfreflective side of the individual. Through teamwork and the fusion of the "I" and "me", feelings of solidarity and group belonging can emerge. The individual will then experience a feeling of complete identification with the others in the group. Mead's concept is also useful for understanding the phenomenon of social solidarity and expands upon Durkheim's explanation of this idea. 
American sociologist, Herbert Blumer (1900-1987), is best known for his academic contributions involving symbolic interactionism. The term symbolic interactionism was coined by Blumer in an article he contributed to Man and Society in 1937 (Blumer, 1969). Symbolic interactionism posits that individuals typically organize their conduct in agreement with their expectations of others and depending upon their familiarity with the situation (Armstrong, 2007). Symbolic interaction can also be explained as a presentation of gestures and a response to the meanings of those gestures (Blumer). The meaning of things for a person grows out of the ways in which other people act toward the person with regard to the thing. Thus, symbolic interactionism views meanings as social products, as creations that are formed in and through the defining activities of people as they interact. The individual's actions are built up through their interpretation of the situations in which they are placed. Structural features, "such as culture, social systems, social stratification, or social roles, set conditions for the actions but do not determine the action" (Blumer, p. 88). Blumer's position provides for individual agency and suggests that individuals do not actually act toward culture or social structure, but rather toward situations. Social organization "enters into action only to the extent to which it shapes situations and supplies fixed sets of symbols which people use when interpreting their situations" (Blumer, p. 88). Group activity, such as sport, is not a mere arena for expression of pre-existing factors; but rather a formative process. For some, sport participation symbolically defines the group and provides meanings that will guide and direct the future action's of the members.

Peter M. Blau's social exchange theory is concerned with reciprocal relationships between individuals within social structures. Blau argues that social exchanges build trust 
over time and they are meaningful (Allan, 2007). In other words, the action has meaning and implies or signifies something beyond itself. Blau sees exchange as the starting mechanism for social interaction and group structure. Before group identities and boundaries, and before roles, status positions and norms are created; interaction is initiated in the hopes of gaining something from the exchange (Allan). This theory can be applied to situations where international students participate in sport alongside native students. The activity facilitates the exchange of norms and builds trust between the two groups of participants. Sport participation, often associated with prestige or power, can also facilitate the exchange of social capital (Light \& Kirk, 2001; Majumdar, 2003). Milton Gordon's (1964) Assimilation in American Life provides an excellent analysis of immigrant behavior and inter-group dynamics in the United States. As part of this study, Gordon carried out a series of interviews with officials of inter-group relations and intra-group communal life organizations in the US. Among these groups were councils and committees representing Jewish, American Indian, Japanese, Negro, Italian, Catholic, and Protestant communities, as well as inter-group organizations. He states that these groups primarily dealt with day-to-day problems and were concerned with discrimination issues; however they did not display a strong understanding of social structures, theories and assimilation models. Gordon discusses and critiques the concepts and rhetoric of "total assimilation", "the melting pot", and "cultural pluralism" theories. Using these ideas as a starting point, he then builds his thesis by providing an in depth analysis of social structure and culture, subcultures, the nature of assimilation, theories of assimilation, the assessment of these theories, and finally; the implications. 
While creating the framework for his thesis, Gordon refers to "the subsociety created by the intersection of the vertical stratifications of ethnicity with the horizontal stratifications of social class as the ethclass" (Gordon, 1964, p. 51). An individual's ethclass might be "upper-middle class white Protestant, or lower-middle class white Irish Catholic, or upper-lower class Negro Protestant, and so on" (Gordon, p. 51). Gordon hypothesized that "differences in social class are more important and decisive than differences of ethnic group with regards to cultural behavior" (Gordon, p. 52). He then indicated that social participation with primary groups and primary relationships tend to confine people to their social class subgroup within their ethnic group; to the ethgroup. Also, Gordon seems to feel that people that engage in sustained primary contacts across racial and religious lines, run the risk of being marginalized. What he means by this is that by straddling the lines between multiple ethnic/social groups, the individual is actually not fully a member of any group. In his discussion on the nature of assimilation, Gordon provides a table that lists the forms or stages of assimilation and includes a corresponding sub-process or condition for each. One of the most common forms is cultural assimilation by substitution where the individual substitutes their heritage and behavior pattern for another. Subordinate immigrants feel pressure to conform to the customs and behaviors of the dominant group. In the substitution model, the minority may participate little or not at all in activities with their own ethnic group. Some immigrants adopt a cultural pluralism model enabling them to participate in societies major institutions (work, school, sport) while still retaining their own ethnic heritage. Throughout his analysis, Gordon references the Anglo-Conformity ideology and indicates that this form of assimilation results in "the disappearance of the ethnic group as 
a separate entity and the evaporation of its distinctive values" (Gordon, 1964, p. 81). Gordon also appears to reject the notion of the "melting pot" theory and refers to it as rhetoric embedded into the American response to turn of the century immigration. While Theodore Roosevelt and Woodrow Wilson favored this ideology, Gordon views it as suggesting that immigrants are absorbed into mainstream American culture. Gordon challenges this notion and indicates that there are numerous "melting pots" or subsocieties, rather than a single American "melting pot". The theory of "cultural pluralism" is more embraced by Gordon, as he points out numerous societies within societies in the US. Immigrant groups often embrace the political and economic life, the common language, usually even the clothing of mainstream America, however; they maintain ties to their ethnic group through religious worship, holidays, meals, music, games, and other activities unique to their ancestry. The point that Gordon is trying to make throughout Assimilation in American Life is that Americans are not just individuals with psychological characteristics. They belong to "primary groups, secondary groups, family groups, social cliques, associations and formal organizations, racial, religious, and national origins groups, and social classes" (Gordon, p. 234). The "nature of these groups and their inter-relationships has a profound impact upon the way in which people of different ethnic backgrounds regard and relate to one another" (Gordon, p. 234).

Sport and Immigrant Adaptation Stodolska and Alexandris (2004) analyzed the recreational sport participation behavior of first and one and a half generation Korean and Polish immigrants residing in Chicago and Urbana-Champaign, Illinois. Milton Gordon's seminal work, Assimilation in American Life, was incorporated into the researchers' theoretical frame. Gordon's 
assimilation model suggests that through participation in mainstream sport, immigrants adopt values and behaviors of the culturally dominant group (Stodolska \& Alexandris).The researchers conducted semi-structured in-depth interviews with 30 immigrants (19 Korean and 11 Polish). Utilizing constant comparative method for analysis, the researchers identified major themes regarding the role of recreational sport in the immigrants' adaptation. The level of involvement in recreational sports was primarily impacted by the immigrant's ethnicity and social class, but also by their gender and time spent in the United States.

Typically, after the immigrants passed through their initial period of adaptation, sport participation increased. The data suggested that middle-class Korean and Polish interviewees were more likely to utilize sport as a vehicle for assimilating to the life of the White American middle class mainstream than their blue-collar counterparts. Sport activities facilitated inter-group contacts and breaking barriers between first generation immigrants, other ethnic minority members, and mainstream White Americans (Stodolska \& Alexandris, 2004). Several Polish interviewees noted that the first time they interacted with mainstream White Americans in an informal setting was during sporting activities. Some interviewees indicated that sport participation helped to solidify their ties with their ethnic community and served to facilitate the retention of ethnic identity. Stodolska and Alexandris' study showed that "participation in traditional sports strengthened community bonds and allowed Korean and Polish immigrants to socialize with individuals whom they shared common culture and experience" (p. 404). Asian Americans are one of the fastest growing minority groups in the United States. While there has been significant growth in scholarship regarding Asian 
Americans, study of their sporting experiences has been neglected (Lee, 2005). According to the 2000 US Census, there were 1,076,872 Koreans residing in the United States (Lee). Lee conducted a study at a large Midwestern university located in an area with a growing Korean American population. All of the participants were females either born in Korea or have parents that were born in Korea. Interviews were tape-recorded and incorporated semi-structured, open-ended questions, although there was some flexibility in this in order to create a free exchange of dialogue with the researcher whom is also of Korean descent. Results suggest that being members of the broader Asian American community impacted Korean Americans as they were heavily influenced by the dominant culture's perception of them as simply being people of Asian descent. Korean Americans "may experience marginalization, and like other Asian Americans, experience dual identities: one relating to race, the other relating to nationality" (Lee, $p$. 483). The sporting experiences of the Korean American women in this examination often display a pattern of dual identity (Lee). The participants found themselves in an unsettled position in American society, feeling as if they are perpetual foreigners.

Participants revealed that they at times felt frustrated with their lack of full acceptance by White Americans (Lee, 2005). It was apparent that the participant's unsettled position in American society provided the foundation for these women to make conscious choices about the sports in which they selected for participation. Sport, consequently, played a vital role in the process of finding their place in American society. A lacrosse player seems to have selected her sport as a symbolic expression of her rejection of Asian American stereotypes. Other participants indicated that they saw Tae Kwon Do, a traditional Korean martial art, as a vehicle for strengthening ties to their 
ethnic background and expressed pride in their culture during the interviews. Another participant explained that she joined a dance sport team as a means for assimilating into the dominant society. The dance team enabled her to come into contact with non-Korean Americans and become more outgoing and socially aware. These interviews indicate that cultural negotiations involved the process of constructing a sport-based identity as a member of a racial and ethnic minority group.

Burdsey (2008) provided a case study of the Amsterdam World Cup (WK Amsterdam), which is an amateur soccer competition and multicultural festival held annually. Framing the event within the context of the Dutch integration policy, Burdsey analyzed various conceptions of identity, community, and multiculturalism displayed by the participants and organizers of the event. WK Amsterdam is a men's soccer tournament which involves the city's diverse immigrant and refugee community. African, Middle Eastern, South Asian, and Caribbean countries are well represented, many of which were former Dutch colonies. However, the tournament organizers make a conscious attempt to ensure that the tournament is not dominated by Eurocentric expression. The researcher addresses three main issues through his observational field work and interview sessions. First, the researcher examines the effectiveness of the event at providing a time and space for community mobilization and the expression of ethnic, national, and gender identities. Second, there is an examination of whiteness and national identity, and the role that WK Amsterdam plays in facilitating the expression of oppositional post-colonial identities. Third, Burdsey evaluates the tournaments potential for the promotion of multi-cultural expression, cultural interaction, and integration into a metropolitan Amsterdam identity. 
WK Amsterdam is reveled as playing an important social role for all the represented communities, particularly for non-white minorities (Burdsey, 2008). The event facilitates valuable face-to-face interaction for communities. Athletes and spectators alike, express their cultural identity. However, much of the researcher's focus is on the spectators. Many come to the event dressed in traditional costumes, participate in live musical performances and dances, offer different types of cuisine, and display flags from their homeland. Amsterdam's diverse ethnic minority populations display their desire for status and a sense of recognition within the community. While white players and spectators are in the minority at the event, WK Amsterdam is organized and produced almost exclusively by whites (Burdsey). Also, a handful of young Dutch males attended the event wearing national team jerseys with the names of popular, White Dutch soccer players printed on the back. Burdsey questions the intentions of these individuals exhibiting their Dutch identity in this space. This can be interpreted by some spectators as an attempt to reaffirm White authority since WK Amsterdam is intended to be a celebration of immigrant cultures (Burdsey).

Burdsey (2008) then provides numerous examples that suggest the structure of the event and situations surrounding the event limit the effectiveness of the organizer's mission in facilitating solidarity. The sheer size of the venue allows, and possibly encourages, teams and spectators to spread and keep separate. Also, by encouraging spectators to affiliate with a single team, the organizers limit the success of the project. Still, the researcher is of the opinion that WK Amsterdam is more effective at embracing multi-cultural ideals and facilitating group cohesion than the majority of mainstream sporting events. 
Bachay (1998) asserts that newly arrived immigrants to the United States are not socialized to the behaviors of the dominant culture, thus they may experience feelings of anxiety, confusion, fear, helplessness, and homesickness. Bachay's study examines the effects of a preventative, psycho educational, counselor intervention on the ethnic identity development of urban Haitian adolescents in the United States. An individual's ethnic identity development is entangled with an individual's perception of group belonging. Through years of counseling Haitian youth, the researcher discovered that rejection of the Haitian immigrant youth by dominant culture and minority peers compels Haitian youth to consistently distance themselves from their own culture. In order to disown their heritage, Haitian youth reject their native language, foods, games, and sports as well as religious and cultural expressions that might reveal evidence of their Haitian culture (Bachay). It is interesting that soccer clubs remain a popular activity for Haitian adult males in South Florida, but the sport is losing appeal among Haitian youth there. Many Haitian-American youth have adopted American football as their sport in order to gain acceptance from their peers. The pressure to conform and assimilate into American culture can have a profound impact on the sporting behavior of immigrant groups.

Bachay (1998) claims that ethnic identity has been neglected by researchers examining adolescents. Bachay utilized The Multigroup Ethnic Identity Measure (MEIM; Phinney, 1992) in order to assess the subject's ethnic identity while also conducting a background survey for demographic data and open ended questions that would aide in the understanding of their experiences. Results indicate that gender significantly impacts ethnic identity in Haitian youth. Haitian boys are "deeply immersed in their search and have not made the commitment vital for the acquisition of a fully realized ethnic identity" 
(Bachay, p. 101). The qualitative open-ended questions also revealed problems. Bachay identified prejudices toward Haitians by African American peers, the language barrier, immigration policies, and poor self-esteem provided further difficulties. Haitian students revealed that they are often too ashamed to identify themselves as Haitian. The researcher stresses the importance of the role that school and community counselors can play in supporting the development of these children and it is possible that some Haitian immigrants will require lifelong intervention.

\section{Sport and Cultural Identity}

Culture is the means through which communities perceive and develop their identity (Giossos, 2008). Modern sports "constitute one of the numerous forms of culture which provide a vehicle for meaningful expression and communication" (Giossos, p. 53). Sport participation serves as the identity bearer while at the same time contributing to the construction and reproduction of a significant part of an individual's identity (Giossos). Giossos' study examines the social conditions under which refuges founded a soccer club in the Greek city of Volos in the early 1920s. More specifically, the soccer club "Niki Volou" is studied in order to understand why this particular club was created and the role that it played in the refugee community. Newspapers and archival documents were examined and personal interviews were conducted in order to investigate the topic.

After the end of World War I, the allied forces created the small, in territorial terms, country of Turkey. However, Greece continued its military operations in Asia Minor, but in 1922 the Turks counter-attacked and managed to remove the Greek military from their lands. The defeat of the Greek army and its subsequent departure from the region resulted in the exodus of tens of thousands of Greeks who sought refuge in 
mainland Greece. The majority of these refugees settled in the area of Macedonia, but also in urban areas such as Athens, Thessaloniki, and Volos. The first establishment of a soccer team by these refugees was in 1923 in the city of Volos. The initial name of the soccer club was "American Red Cross Refugee Union" after the organization which had donated money and resources to help them. The soccer team held great importance for the refugees and one archival source explains that the only things the refugees took with them when they relocated was the icon of Mother Mary from their church and their soccer team (Giossos, 2008). The team adopted a black and yellow color scheme in order to emphasize their Byzantine cultural background.

Households in the settlement would take turns washing the players' shirts for a week and men volunteered to construct the soccer field in a central locations surrounded by homes in the community. Because of societal stigma, the club later determined it would be best to remove the refugee label from their team name and renamed the club "Niki Volou"; however the team is still firmly embedded into the refugee supporters" identity. The name was suggested by one member as a result of the statuette of Apteros Niki being displayed on the wall in the athletic club. The fact that "Niki" was also the emblem of Panionios of Smyrna, the athletic club in Turkey where the refugees relocated from; gave additional leverage to this proposal. Thus, the name "Niki" was selected, "as it constituted an overall expression of the refugees' ideology and psyche" (Giossos, 2008, p. 58). A network of social relationships within the refugee community was emphasized and it was important that new members did not come in and alter the uniformity of the team. Players from the team enjoyed status and respect in the community and the team was responsible for the preservation of their unique cultural identity. The researcher also 
explains that their rival team "Olympiakos Volou" symbolically served as the cultural other which further aided the communities' development of identity and social meaning. This dynamic is common in situations where two rival teams have distinct cultural identities.

Glasgow Celtic was established in 1887 and is one of the more recognized soccer clubs in Europe. Historically the fan base for the team is derived from the immigrant Irish community in Glasgow. Celtic's great rival is Glasgow Rangers, and unfortunately; this bitter rivalry has been associated with sectarian problems. Matches between them are not simply a clash of two soccer powers, but a clash of cultures and ideologies (McMenemy $\&$ Poulter, 2005). Rangers are the traditional protestant team while Celtic is championed by the Scottish Catholics. McMenemy and Poulter administered a survey utilizing two email lists for Celtic fans in order to assess the affiliations, expressions of identity, and attitudes of Scots of Irish descent. The survey obtained demographic data and offered open ended questions. Of the 700 Celtic supporters e-mailed, 108 participated in the study.

It was not surprising that Glasgow Celtic was revealed by many to be a point of attachment for expressing their Irish identity and pride. However, the prevailing sentiment from the collection is one of a community that feels it is not encouraged to celebrate its Irishness by Scottish society, something it does through supporting the Celtic soccer team. Still, the majority of the participants indicated that they support the Scottish national soccer team and do not perceive any conflict in supporting Scotland and Celtic. A sizeable number of participants indicated that they remain loyal to Ireland in both national identity and national team support, despite many of them being third or fourth 
generation immigrants (McMenemy \& Poulter, 2005). For these individuals, their support of Celtic was not seen as being compatible with Scottishness. Regardless, the impact of Celtic on the identity of Scots with Irish heritage is important to examine. Support of Celtic provides an opportunity to express pride and solidarity in the Irish Catholic community.

Through his ethnographic-historical examination, Stoddart (2006) asserts that Barbadian cricket is the most striking and tangible product of Barbados' colonial heritage. Barbados is recognized as the most prolific per capita producer of elite cricket players in the world and for many of the country's citizens, cricket is a cultural institution. Cricket has been, and continues to be a major determinant of cultural relationships between the dominant minority and the larger subordinate community (Stoddart). This helps to reduce potential conflicts between these two groups in Barbados. The sport of cricket also has served as a vehicle for the preservation of $19^{\text {th }}$ century social relationships well into the $21^{\text {st }}$ century, which reveals the power of culture in the face of wider economic and political changes.

Stoddart (2006) traces the history of Barbados as well as cricket's place in the nation's society and culture. Stoddart incorporates the work of Gramsci and Bourdieu in addressing the concepts of cultural domination and the relationship between sport and social class. He asserts that cricket has been a major influence in Barbadian cultural evolution revealing that the game's emergence coincided with the Barbadian ruling order's search for a moral authority. Cricket is not a mere game or physical activity; participation symbolizes a belief system and subscription to specific social conventions. Cricket manuals provide advice on social etiquette and behavior. This enables cultural 
modeling through sport. British cultural values, morality codes, attitudes toward social ranking, and behavioral standards can be instilled into the Barbadian population through cricket. While Barbados is a small nation in territory and population, the island possess an unusually elaborate cricket organization strongly defined by its social heritage. Cricket supplies an avenue for the meeting of individuals of different race, color, and class groups. Also, there are numerous examples of Black cricket heroes in Barbados, whom are widely celebrated by members of the community regardless of color and class. Thus, distinguished Black cricket players in Barbados have attained social capital through sport. Also, cricket has provided an ongoing relationship between two quite different cultural traditions through carefully regulated social meeting points. This helps to reduce areas of possible conflict and facilitates group solidarity (Stoddart).

The success that the Turkish national soccer team experienced during the 2002 World Cup held in South Korea and Japan was a phenomenal event in the history of Turkish sport (Kösebalaban, 2004). Kösebalaban asserts that sport has been used by the media as a mechanism for drawing the boundaries of Turkish national identity. The researcher explains that "boundary marking is achieved through emphasizing and magnifying feelings of 'us' versus 'them' throughout the media's coverage" (Kösebalaban, p. 47). The prevailing theme in the headlines of both the Islamic and the secular media is a characterization of Europe as the 'other' of Turkish national identity. The media frames these sport encounters with high levels of patriotism and national fervor "while reinforcing the mental imaginations of belonging to a supranational cultural identity" (Kösebalaban, p. 47). Turkey became a member of UEFA (Union of European Football Associations) in 1962, however; up until the late 1990s Turkish teams were 
viewed as easy underdogs by the much stronger European teams. Also, prior to the 2002 World Cup, the last time Turkey qualified for the World Cup was in 1954.

Turkish media consistently indicates a lack of identification with Europe and reflects feelings of historical superiority as well as modern inferiority (Kösebalaban, 2004). Sporting events versus European teams typically make use of nationalistic historical references regarding the time of the Ottoman Empire and emphasize distinct 'us' versus 'them' sentiments. In the 2002 World Cup, Turkey played all of its games against non-European teams. Three of their rivals were Asian countries; China, Japan, and South Korea. Their other rivals were Costa Rica, Senegal, and Brazil. Turkey made it into the semi-finals and after losing to Brazil, finished in third place. Much of the media coverage applauded Turkey's opponents and framed them as friendly while Europeans teams were depicted as 'uncivilized'. The conservative Islamist press stressed the international prestige that Turkey was gaining through their World Cup success. The media also stressed that the team's accomplishments were not a result of the power of 'Turks' but rather to that of Turkey as a whole (Kösebalaban). After each successful match, crowds celebrated in city squares all over the country, including Kurdish cities like Diyarbakir. Turkish television stations stressed the notion of solidarity while broadcasting these celebrations attempting to create an effect of national unity. In order to stress national unity, one must also stress the differences and characteristics of the 'others', in this case Europeans. In conclusion, soccer provided Turkey with a politically neutral point of attachment for their diverse society to re-define their boundaries of national identity (Kösebalaban). Capitalizing on Turkey's success in the 2002 World Cup, the media seized this opportunity to transmit messages regarding cultural identity. 


\section{Sport and Social Capital}

The sport of rugby remains a highly visible element in the sport curriculum of elite private schools in Australia. Private schools "of the social elite have been identified as key institutions through which families and social groups reproduce social advantage" (Light \& Kirk, 2001, p. 81). Rugby is utilized by these schools for the "instillation of upper-class masculinity and for the gains in distinction this form of masculinity brings to these schools" (Light \& Kirk, p. 81). The authors have incorporated the work of Pierre Bourdieu into their theoretical framework for this study and note that his concepts of habitus and capital have been effectively applied to a wide range of studies in the realm of sport. Bourdieu's concept of habitus refers to "a set of dispositions, inclinations, and schemes of perception with which an individual interprets social situations" (Light \& Kirk, p. 83). Capital refers to things of cultural value in this study. Social capital can be accumulated through established social connections and then can be converted into economic capital.

The researchers draw on these theoretical constructs in order to understand and interpret the meaning of rugby at a prestigious private school in Brisbane, Australia. For the purposes of their study, they refer to this school as The Brisbane School (TBS). The researchers visited the school regularly during the 1997 and 1998 rugby seasons and gathered data through observational field work, conversational interviews, and quantitative video analysis of games. Additionally, the researchers were able to obtain data in 1998 from former members of the 1997 team who were well established in their careers. Their analysis revealed that enduring difficult practices and games pulled the team together through collective suffering for a common goal. Maximum effort and 
aggression, while always playing within boundaries framed by the formal rules of play; was expected from all players. The strong interpersonal bonds developed through rugby resulted in long lasting friendships. Former players that had risen to positions of power in the corporate world, typically in law or accounting, were inclined to employ and establish business contacts with other former players who shared similar values and behaviors. Also, being a former rugby player at an elite private school seemed to convey particular meaning to prospective employers. The prospective employers identified these young men as committed team players, leaders, and winners. As a result of their similar background, the players appear as if they will fit in with the culture of the firm. Light and Kirk conclude that engagement in rugby at schools such as TBS enables privileged young men to develop the physical capital that constitutes class specific habitus. Former rugby players that graduate from elite private schools in Australia are able to develop business contacts that enhance their accumulation of economic capital

Indian cricket, at the national level, is dominated by the economically privileged, affluent division of society. The economically privileged echelon has been for decades, and remains, upper-caste (Majumdar, 2003). The connection between caste and class is typical in Indian society. Contrary to assumptions that cricket participation has always been restricted to the English-speaking, educated, affluent, Indian aristocracy; cricket in colonial India was actually more representative of Indian society as a whole (Majumdar). The researcher traces the history of cricket in India from the time it was first introduced by British imperialists to the post independence corporate model of cricket that presently exists. Prior to India's independence, cricket players that made their way to the highest level came from diverse cultural and economic backgrounds. Many of the most famous 
players came from modest origins, some of which coming from lower-caste, economically deprived backgrounds. During the formative stages of cricket in India, athletic skill in the sport symbolized a ladder for social mobility among the underprivileged. This resulted from both princely patronage in India as well as British patronage of the sport. These patrons ignored caste, color, and economic prejudices and recruited players based on merit (Majumdar).

Shortly after India gained its independence in 1947, corporate sponsors transformed cricket into a preserve of the educated elite and relatively affluent (Majumdar, 2003). Companies that employed cricket players had clear policies regarding their recruitment. They were concerned with employing educated men that would continue to benefit the corporation upon retiring from the sport. Academic qualification began to play an important role in determining a player's salary. Additionally, cricket clubs began to charge high fees, allowing the wealthy to monopolize the sport by preventing underprivileged Indians from playing. Ticket prices to attend matches also increased, making the cricket stadium the preserve of the affluent. This has lead to the perpetuation of the view that cricket was and is the game of the elite, while soccer and field hockey are the sports played by those from humble origins. In reality, statistics reveal that prior to independence, many of India's noted soccer and field hockey players also played cricket (Majumdar). The representative nature of cricket in colonial India promoted cooperation and solidarity between the elite and underprivileged. Today the sport has been monopolized by the educated elite and is utilized for the reproduction of societal advantages. Examining the relationship between sport participation and cultural capital indicates there is a need for practitioners to develop greater inclusionary practices. 
International Students and Physical Activity

Yoh, Yang, and Gordon (2008) examined the frequency of participation in physical activity among international students attending American universities. The researchers obtained a sample of 521 international students from five different universities in the Midwest. On average, the international students participating in this study spent 3.4 hours participating in physical activities per week. The operational definition of physical activity used in their study encompassed a wide spectrum, ranging from competitive and structured events to any informal or unstructured form of exercise, sport, or recreation not associated with one's job duties (Yoh, Yang, \& Gordon).

Results from the questionnaire revealed that students from North America (i.e., Canada and Mexico) participated in physical activity the most. This group was followed closely by students from Europe and then students from South America. Students from Asian and African countries spent significantly less time participating in physical activities than international students from other continents. When examining the interaction between gender and origin of the international students, females from Asian countries spent significantly less time participating in physical activities than any other group. African females spent more time engaged in physical activities than Asian females; however they were less active than female students from North America, Europe and South America.

Li and Stodolska (2006) examined Chinese international graduate students in order to identify factors relating to their transnational status that might impact their leisure behavior. The theory of transnationalism asserts that modern day migrants maintain social, cultural, political and economic affiliations with their nation of origin 
while studying or working abroad (Li \& Stodolska). The researchers conducted interviews with 16 Chinese graduate students attending the University of Illinois at Urbana-Champaign. At the time that the study was conducted, the university had 881 graduate students from China enrolled.

Through analysis of the qualitative data obtained, the researchers identified three central themes regarding the relationship between transnationalism and leisure behavior. First, the temporary status of the Chinese graduate students impacted their leisure behavior. Students explained that they were attending an American university primarily to focus on their studies and research, thus improving their career opportunities when they return home. The academic priorities of the participants suggest that there was virtually no time for leisure. Second, the emotional status of the Chinese graduate students impacted their leisure behavior. Many felt that their time constraints and academic pressures spilled over into their free time resulting in a prevalent displeasure with life. The students expressed that they were psychologically consumed by their work which prevented them from enjoying any leisure opportunities that they had. Third, the legal status and travel situations impacted their leisure behavior. Strict visa requirements and an inability to take pleasurable trips forced the subjects to defer leisure activities until after their degrees were completed. Considering that sport is one area within leisure behavior, it is reasonable to think that transnationalism might impact recreational sport participation and sport spectatorship.

\section{Instrumentation}

The importance of examining ethnic variables and their impact on consumption behavior is supported by the global, multicultural context found in numerous 
industrialized countries (Pons et al., 2001). Sport and sporting events are recognized as having a key relationship with the values and culture of many countries and they signify important meanings for individuals (Pons et al.). Pons et al. developed a scale to assess the linkage between ethnic variables and sport consumption. Their instrument also examined the social role that sport plays in multi-cultural societies and the role that sport plays in immigrant adaptation.

Utilizing a cultural-pluralist approach, Pons et al. examined the relationship between soccer and the Italian Canadian community in Montreal and the relationship between hockey and the French Canadians located in Quebec City. Their questionnaire included three measurement scales representing the constructs of acculturation (ACC), ethnic identity (EI), and orientation toward sporting events (OSE). Their acculturation construct was based on the bi-level assimilation model. Their ethnic identity construct included three factors; language use with family, interaction and social involvement in the subject's ethnic community, and religious affiliation. The orientation toward sport events construct considered three dimensions; the role of sporting events as a provider of sensations, the capacity of sporting events to fulfill particular cognitive needs, and the socialization properties of sporting events. There were 37 items under 3 constructs measured on a 5-point Likert scale. The orientation toward soccer and hockey was measured for each subject. The instrument also measured other behaviors associated sport consumption such as purchasing patterns and time spent at sporting events. Lastly, demographic data was obtained. The reliability coefficients (Cronbach's alphas) were assessed for the instrument and all the dimensions were above the .8 threshold for acceptance. 
Results from the study revealed that French Canadian respondents were more oriented toward hockey while Italian Canadians were oriented toward soccer. Additionally, ethnic identity was positively related to soccer consumption and acculturation was positively related to hockey consumption. The researchers hypothesized that highly acculturated immigrants would present orientations similar to both the host culture and the culture of their heritage with regards to their favorite sports. Data obtained through their instrument supported this hypothesis by indicating that highly acculturated Italian Canadian hockey fans shared a similar orientation profile to that of French Canadians. At the same time, highly acculturated Italian Canadian soccer fans shared similar orientation profile to that of their less acculturated Italian Canadian peers.

The Latino community is the fastest-growing segment of the United States population and is also the nation's largest minority segment (Harrolle \& Trail, 2007). Harrolle and Trail examined the relationship between ethnic identity, acculturation, identification with specific sports, and identification with sports in general for Latinos residing in the United States. Mead's identity theory (1934) was incorporated into their theoretical frame. Data was collected from 373 Latino participants at various locations including Latino restaurants, doctors' waiting rooms, and a Latino outdoor music festival. The researchers utilized three existing scales when developing their instrument. First, Roberts et al.'s (1999) version of the Multigroup Ethnic Identity Measure (MEIM) was incorporated in order to understand ethnic identity across their sample. Second, Zea et al.'s (2003) Abbreviated Multidimensional Acculturation Scale was utilized to measure identity, language competence and cultural competence. Third, Robinson and Trail's 
(2005) Point of Attachment Index (PAI) was adopted to measure how attached the subject was to a specific sport and to sport in general. The attachment construct is also described as the degree to which an individual identifies with sport or a particular sport. The final version of their instrument contained 27 items randomly placed on the questionnaire on a 7-point Likert scale.

Structural Equation Modeling (SEM) was utilized to test the confirmatory factor analysis of the total measurement model (CFA). Results of the CFA indicated a close fit and the Cronbach's alpha reliability coefficients were good for all constructs in all three scales ranging from .80 to .94 . They then tested four proposed models that were based on findings from previous researchers in various settings. All four models used fit the data well. The results of the study indicated that the majority of Latinos participating in the study were highly acculturated with the dominant US society. Acculturation had a small influence on the subject's identification with American football, baseball, basketball and sport in general. Also, as the ethnic identity of Latinos increased, their identification with hockey decreased. Interestingly, even when levels of ethnic identity and acculturation varied, attachment to soccer remained the same. The researchers concluded that for Latinos as a whole, ethnic identity and acculturation had a greater impact on their identification with American football than for all the other sports examined.

Summary

The purpose of this literature review was to provide a comprehensive examination of sport as a vehicle for socialization, maintenance of social capital, and expression of cultural identity. Stodolska and Alexandris (2004) reveal that sport has played a considerable role in the adaptation process of Korean and Polish immigrants in Chicago 
and Urbana-Champaign, Illinois. Burdsey (2008), Giossos (2008), Lee (2005), McMenemy and Poulter (2005), and Bachay (1998) also assert that sport plays an important role in the adaptation process of immigrants. While Milton Gordon's Assimilation in American Life was not cited by these researchers, his concepts and theories are highly relevant to the topic. Throughout Gordon's book he discusses the pressures toward conformity that immigrants experience and reveals the impact that these pressures have on their attitudes and behaviors. Lee's (2005) examination of Korean American women in the United States suggests that stereotyping of Asians by the dominant culture and pressures toward conformity can impact the sporting behavior of immigrant females. Some will participate in sports that will enable them to challenge stereotypes and socialize with those of the dominant culture; others will participate in sports that are associated with their heritage in order to strengthen ties with their ethnic group. Bachay's (1998) study also reveals that discrimination toward immigrant groups can impact sport selection. In Bachay's study, young Haitian Americans, particularly males; consistently rejected their native culture and disowned their heritage. The sports which they previously played, primarily soccer, were abandoned as this might reveal evidence of their Haitian heritage. At the same time, participation in mainstream sports like American football facilitates the assimilation process for Haitian youth.

Giossos (2008), McMenemy and Poulter (2005), and Kosebalaban (2004) reveal the power that sport plays in expressing pride in one's culture. The groups in these studies utilized their affiliation with a soccer team to maintain their cultural identity and internalize feelings of solidarity. Durkheim's writings on solidarity are applicable to these studies as the groups examined utilized sport as a point of attachment for maintaining 
solidarity in their respective communities. Light and Kirk (2001) and Majumdar (2003) examine sport as a vehicle for attaining and maintaining social capital. Examinations of rugby at elite private schools in Australia and the corporate model of cricket in India suggests that sport participation allows members of the privileged elite to distance themselves from the middle and lower classes. Through participation in these sports, the athletes are provided with societal advantages that can then be converted into economic capital. Bourdieu's concept of habitus and analysis of social capital provides further support for the argument that sport allows for the reproduction of societal advantages. While many of the studies examined indicate that sport can serve as a powerful vehicle for assimilation and facilitate integration; it can also be utilized by elite members of society as a mechanism for keeping the subordinate groups on the outside looking in. Yoh, Yang, and Gordon (2008) examined the frequency of participation among international students attending American universities. Their results indicate that both ethnicity and gender impact frequency of participation. Li and Stodolska (2006) examined Chinese graduate students attending a large university in the Midwest. Utilizing the theory of transnationalism, they revealed that the migrant status of Chinese graduate students impacted their leisure experience primarily by reducing their frequency of participation and enjoyment in leisure activities.

Pons et al. (2001) developed a scale to measure the relationship between ethnic identity and sport consumption. Results from their scale provide further support to the argument that cultural identity helps to explain the sport participation and consumption behavior of immigrants. Harrolle and Trail (2007) incorporated three existing scales into one instrument in an attempt to explain the impact of ethnic identity and acculturation on 
Latino American's attachment and with sport. Through rigorous psychometric properties testing, they revealed that four different hypothesized models all fit the data well. Results from their study suggest that ethnic identity and acculturation had minimal impact on the sport identification of Latinos. 


\section{CHAPTER III}

\section{METHODOLOGY}

This chapter includes a description of the methods and procedures that were used to examine the sport participation behavior of international students with regards to socialization, maintenance of cultural identity, and assimilation. Demographics, frequency of participation, sport selection for participation, and sport spectatorship are also examined. The following sections are included: (a) research design, (b) participants, (c) instrumentation, and (d) procedures.

\section{Research Design}

This study utilized a mixed survey design. The independent variables of the study include information regarding the subject's demographics and length of time in the United States. Demographics include age, nationality and gender. The dependent variables include four factors regarding sport participation behavior, sport selection for participation, and frequency of participation. The four factors assessing sport participation behavior are: 1) participate with same cultural background, 2) participate with different cultural background, 3) participate to retain cultural identity, and 4) participate to assimilate into new culture. These four factors are based on Durkheim (1960) and Mead's (1934) theories on social solidarity and identity, Blumer's (1969) theory of symbolic interactionism, Blau's (1964) social exchange theory, and Gordon's (1964) theory of assimilation and sub-processes. Sport selection for participation refers to the particular sport(s) that the subject most frequently engages in. Frequency of participation is the number of times per month that the subject physically engages in sport. Qualitative information was also obtained by providing the subject an opportunity 
to describe their personal experiences participating in sport in the United States as it relates to socialization and opportunities to adjust to their new environment. Subjects were also requested to provide their personal definition of 'cultural identity'.

\section{Participants}

The participants within this study included all international students attending The University of Southern Mississippi, Kansas State University, the University of NevadaLas Vegas, and Florida State University that voluntarily responded to an online survey distributed to them via their universities' international studies department. However, varsity athletes participating in intercollegiate sports were requested not to respond to the online survey. Written permission from the university's international studies office and Institutional Review Board (IRB) approval was obtained. These four universities were selected because they are large comprehensive universities with undergraduate, masters, and doctoral students, thus providing a representative sample of students from a variety of degree programs. Also, these particular universities allow the researcher to assess international students located in different geographic regions in the United States. Lastly, the universities in this study were very enthusiastic about the research topic and indicated that the data obtained would provide useful information for their international studies office as well as their campus recreation department.

\section{Instrumentation}

The survey instrument that was utilized in this study was developed by the researcher through a review of relevant literature, recommendations from an expert panel, results from a focus group, content validity testing, and modification of the preliminary scale. The expert panel included Dr. Jay Coakley, Dr. Joy DeSensi, and Dr. Yiannis 
Giossos. The survey consisted of six parts: Part I: Sport and Cultural Identity Scale (SCIS), Part II: Demographics, Part III: Sport Selection for Participation, Part IV: Frequency of Participation, Part V: Sport Spectatorship and Media Consumption, and Part VI: Qualitative Data. The instrument as a whole is referred to as the International Students Sport Participation and Consumption Survey.

Part I: Sport and Cultural Identity Scale (SCIS) contained a total of 24 items (four- point scale) under four factors. There were six items under each factor. The 'participate with same cultural background' factor was supported by theories of social solidarity and identity. The 'participate with different cultural background' factor was supported by social exchange theory. The 'participate to retain cultural identity' factor was supported by the theory of symbolic interactionism. The 'assimilate into new culture' factor was supported by Gordon's theory of assimilation and sub-processes (1964).

Part II: Demographics included age, nationality, gender, and length of time living in the United States.

Part III: Sport Selection for Participation instructed the respondent to rank their top three sports based on frequency of participation. There were sixteen different sports to select from and there was the option of 'other' for respondents that frequently participated in a non-listed sport.

Part IV: Frequency Of Participation was measured by the number of times that the respondent physically engaged in sport per month.

Part V: Sport Spectatorship and Media Consumption instructed the respondent to rank their top three sports based on frequency of spectatorship. There were eighteen different sports to select from as well as the 'other' option. Students were also instructed 
to determine if they most frequently attended live sporting events with individuals of the same cultural background or with individuals of a different cultural background. Lastly, students were asked to determine if they most frequently consumed domestic sport media, foreign sport media, or domestic and foreign equally.

Part VI: Qualitative Data included two additional questions where the international student was encouraged to elaborate: (1) Please provide a brief explanation of the way you define 'cultural identity', and (2) Please provide further details that you feel describe your experiences with sport in the US as it relates to socialization as well as opportunities to adjust to your new environment.

Face and content validity of the entire instrument was evaluated by a panel of three sport sociology experts whom are internationally recognized as preeminent scholars in their field. After receiving feedback from the panel of experts, necessary adjustments were adopted and a focus group was conducted with four English Learning Institute students from the University of Southern Mississippi. The focus group was utilized to ensure that foreign students with English as a second language could accurately comprehend the items.

\section{Procedures}

As previously stated, international students participated in this study by responding to an e-mail message which contained a link to the online version of the survey. All international students with a registered e-mail address attending The University of Southern Mississippi, Kansas State University, the University of NevadaLas Vegas, and Florida State University received a message notifying them of the study through the international studies office at their respective university. Respondents 
completed the survey online and the data was transferred directly to a file that only the researcher had access to. The researcher did not distinguish between which particular university the international student attended. 


\section{References}

Allan, K. (2007). The social lens: An invitation to social and sociological theory. Thousand Oaks, CA: Sage.

Armstrong, K. L. (2007). Self, situations, and sport consumption: An exploratory study of symbolic interactionism. Journal of Sport Behavior, 30, 111-129.

Bachay, J. (1998). Ethnic identity development and urban Haitian adolescents. Journal of Multicultural Counseling and Development, 26, 96-109.

Blau, P. M. (1964). Exchange and power in social life. New York: Wiley.

Blumer, H. (1969). Symbolic interactionism: Perspective and method. Englewood Cliffs, NJ: Prentice Hall.

Bourdieu, P. (1977). Outline of a theory of practice. New York: Cambridge University Press.

Burdsey, D. (2008). Contested conceptions of identity, community and multiculturalism in the staging of alternative sport events: A case study of the Amsterdam World Cup football tournament. Leisure Studies, 27, 259-277.

Durkheim, E. (1972). Restitutive sanctions and the relationship between mechanical and organic solidarity. In A. Giddens (Ed.), Selected writings, (pp. 135-140). London: Cambridge University Press. (Original work published 1960)

Giossos, Y. (2008). Scoring for the homeland: The soccer team of the refugees of Volos. Studies in Physical Culture and Tourism, 15, 53-63.

Gordon, M. M. (1964). Assimilation in American life: The role of race, religions and national origins. New York: Oxford University Press. 
Harrolle, M. G., \& Trail, G. T. (2007). Ethnic identification, acculturation and sports identification of Latinos in the United States. International Journal of Sports Marketing \& Sponsorship, 8(3), 234-253.

Hochschild, J. P. (2006). Globalization: Ancient and modern. Intercollegiate Review, $41(1), 40-48$.

Institute of International Education, Open Doors (2008). International students on U.S. campuses at all-time high. Retrieved May 9, 2009, from http://www.iie.org/

Kösebalaban, H. (2004). Turkish media and sport coverage: Marking boundaries of national identity. Critique: Critical Middle Eastern Studies, 13, 47-64.

Lee, Y. (2005). A new voice: Korean American women in sports. International Review for the Sociology of Sport, 40, 481-495.

Li, H., \& Anderson, M. (2008). Athletic identity in China: Examining the AIMS in a Hong Kong Sample. International Journal of Sport and Exercise Psychology, 6 , 176-188.

Li, M., \& Stodolska, M. (2006). Transnationalism, leisure, and Chinese graduate students in the United States. Leisure Sciences, 28(1), 39-55.

Light, R., \& Kirk, D. (2001). Australian cultural capital-rugby's social meaning: Physical assets, social advantage and independent schools. Culture, Sport, \& Society, 4, 81-98.

Majumdar, B. (2003). Cricket in India: Representative playing field to restrictive preserve. Culture, Sport, \& Society, 6, 169-189.

McMenemy, D., \& Poulter, A. (2005). An identity of two halves? Irish Studies Review, 13, 139-150. 
Mead, G. H. (1934). Mind, self, \& society. Chicago: University of Chicago Press.

Phinney, J. S. (1992). The Multigroup Ethnic Identity Measure: A new scale for use with diverse groups. Journal of Adolescent Research, 7(2), 156-176.

Pons, F., Laroche, M., Nyeck, S., \& Perreault, S. (2001). Role of sporting events as ethnoculture's emblems: Impact of acculturation and ethnic identity on consumers' orientation toward sporting events. Sport Marketing Quarterly, 10(4), 231-240.

Roberts, R. E., Phinney, J. S., Masse, L. C., Chen, Y. R., Roberts, C. R., \& Romero, A. (1999). The structure of ethnic identity of young adolescents from diverse ethnocultural groups. Journal of Early Adolescence, 19(3), 301-322.

Stoddart, B. (2006). Cricket, social formation and cultural continuity in Barbados: A preliminary ethnohistory. Sport in Society, 9, 762-789.

Stodolska, M., \& Alexandris, K. (2004). The role of recreational sport in the adaptation of first generation immigrants in the United States. Journal of Leisure Research, $36(3), 379-413$.

Washington, R. E., \& Karen, D. (2001). Sport and Society. Annual Review of Sociology, 27, 187-212.

Weiss, O. (2001). Identity reinforcement in sport. International Review for the Sociology of Sport, 36, 393-405.

Yoh, T., Yang, H., \& Gordon, B. (2008). Status of participation in physical activities among international students attending colleges and universities in the United States. College Student Journal, 42(4), 1110-1117. 


\section{CHAPTER IV}

MANUSCRIPT ONE

SPORT AS A VEHICLE FOR SOCIALIZATION AND MANTENANCE OF

CULTURAL IDENTITY:

\section{INTERNATIONAL STUDENTS ATTENDING AMERICAN UNIVERSITIES}

James T. Allen

The University of Southern Mississippi

Was submitted to: Sport Management Review

Date of Submission: May 2009 


\section{Introduction}

Sport is one of the few social activities of human beings that can be recognized in virtually every community and culture around the globe as a vehicle for bringing people together (Eitzen \& Sage, 2003). For many, their sport participation is motivated by a desire to be a part of a cohesive group and internalize feelings of belonging. Some participants may only consider health benefits or enjoyment when engaging in sport, but for many the experience is intrinsically connected to their identity and self-concept (Weiss, 2001). Consequently, sport can be utilized as a way of maintaining one's cultural identity (Stodolska \& Alexandris, 2004).

On the other hand, sport can be a vehicle for exclusion and can promote elitism. Those who participate in the culturally dominant sport are awarded with more opportunities for socialization and have greater access to valuable social capital and power (Light \& Kirk, 2001). For example, private schools "of the social elite have been identified as key institutions through which families and social groups reproduce social advantage" (Light \& Kirk, p. 81). Former rugby players from elite private schools that rise to positions of power in the corporate world are inclined to employ and establish business contacts with other former players who share similar values and behaviors. As a result of their similar background, former players appear as if they will fit in with the culture of the firm (Light \& Kirk).

Individuals who are excluded from participating in sport may miss valuable opportunities for socialization, education, and even professional development (Majumdar, 2003). Indian cricket, at the national level, is dominated by the economically privileged, affluent division of society. Shortly after India gained its independence in 
1947, corporate sponsors transformed cricket into a preserve of the educated elite and relatively affluent (Majumdar, 2003). Companies that employ cricket players have clear policies regarding their recruitment. They are concerned with employing educated men that will continue to benefit the corporation upon retiring from the sport. Academic qualifications play an important role in determining a player's salary. Additionally, cricket clubs charge high fees, allowing the wealthy to monopolize the sport by preventing underprivileged Indians from playing. Today, the sport has been monopolized by the educated elite and is utilized for the reproduction of societal advantages. It is important to understand what connects certain groups of people to particular sports activities and what role these play in the reproduction of social and economic inequalities in a given society (Washington \& Karen, 2001). Responsible sport managers must consider the profound relationship between sport participation and social capital. Understanding this relationship allows sport managers to recognize the importance of including underrepresented socio-cultural groups.

Globalization, which has often simply meant Westernization, fosters homogenous societies by marginalizing traditional cultures and ethnic communities (Hochschild, 2006). Despite the fact that sport can be used to promote conformity and express western views, sport can also provide minority groups and foreign nationals with opportunities for keeping cultural ties strong (Giossos, 2008; Lee, 2005). Globalization has also led large numbers of foreign nationals to seek educational opportunities in the United States (Yoh, Yang, \& Gordon, 2008). According to the Institute of International Education (2008), there were 623,805 international students enrolled at American universities for the 20072008 academic year (n.p.). For many of these students, obtaining a quality education and 
developing a lucrative career path is the primary motive for relocating to the United States (Li \& Stodolska, 2006). However, it is important that these students are provided opportunities for socialization, cultural expression, and maintenance of physical health (Yoh, Yang, \& Gordon). Recreational sport can serve a multi-dimensional role for international students. For some, sport may simply be an activity to stay physically fit. Others may utilize sport to retain a sense of their homeland by engaging in a familiar recreational activity with other international students of the same or similar cultural heritage. Also, there may be some international students who view sport participation as an opportunity for assimilating into their new surroundings and new culture. Participating in public activities alongside individuals of the dominant culture facilitates assimilation for individuals of the subordinate culture (Gordon, 1964).

While there have been numerous studies examining the role of sport in the lives' of immigrants (Harrolle \& Trail, 2007; Pons, Laroche, Nyeck, \& Perreault, 2001; Stodolska \& Alexandris, 2004), currently, there is a gap in the body of research as only a few studies have focused specifically on international students. Previous research focused on international students has either concentrated exclusively on one nationality group or strictly examined frequency of participation (Lee, 2005; Li \& Stodolska, 2006; Yoh, Yang, \& Gordon 2008). Thus, there have been no holistic approaches that have examined international students with regards to socialization, cultural identity, and assimilation through sport. Due to the increase in the number of international students and the lack of empirical studies, the need to study their participation in sport is greater than ever. Currently, there is not a scale available for researchers interested in examining factors of cultural maintenance and assimilation as they pertain to international students. The 
purpose of this study was two-fold. The first purpose of the study was to develop a valid and reliable instrument that can be utilized for understanding sport consumer behavior among international students attending American universities as it relates to socialization, cultural identity, and assimilation. The second purpose of the study was to provide an examination of international students' sport participation with regards to maintenance of cultural identity and assimilation. Results from this study would enable American universities to better understand the unique characteristics of international students and their sport participation. Thus, sport can be better utilized as a vehicle for the inclusion of diverse populations into the larger campus community. Furthermore, this study would obtain important information for practitioners involved in programming recreational sport, thus enhancing their ability to target this growing market segment.

\section{Review of Literature}

\section{Theoretical Foundation}

What happens to society when cultural practices, religious beliefs, and political ideologies increase in diversity? There must remain some point of attachment that facilitates group solidarity. Emile Durkheim (1972) insisted that society was greater than the sum of its parts and coined the term collective consciousness. He describes individual's shared beliefs, or the collective consciousness, as a vehicle for maintaining social solidarity and stability. Without this binding of individuals into a cohesive social unit, society would disintegrate; thus resulting in chaos (Durkheim). Mizruchi (1985) utilized Durkheim's theory of solidarity in the sport context and demonstrated that social support and stability is the main determinant in the home advantage for sport teams. For the purposes of the present study, the researchers draw on Durkheim to suggest that 
international students are able to internalize feelings of belonging, stability, and solidarity through participating in sport with others that share their cultural background.

Some researchers examining sport have found a symbolic interactionist frame and identity theory to be useful for their work (Weiss, 2001). This frame and theory emphasize conception of self and describe identity as internalized expectations resulting from roles that are entrenched in organized networks of social interaction (Allan, 2007). Social structures are viewed as facilitators for bringing people into networks or constraints in keeping them out. Identity theory, rooted in the work of George Herbert Mead, is interested in the social basis of meaning, self, and action (Allan). The process of the individual interacting with others in order to create an identity is referred to as identity negotiation (Mead, 1934). The purpose of identity negotiation is to develop a set of behaviors that will reinforce the identity of the individual (Mead). For example, participants in sport are able to display their dexterity, strength, knowledge, intelligence, courage or self-control; qualities that are expected in their social environment (Weiss).

According to Mead (1934), each individual determines his/her behavior in terms of what other individuals are doing. Mead uses an example of a person playing baseball where the individual's actions are determined by his/her assumptions of the others who are playing the game. What the individual does "is controlled by his being everyone else on that team, at least in so far as those attitudes impact his own response" (Mead, p. 154). The organization of these attitudes and actions of the participants provide the individual with his unity of self which Mead refers to as "the generalized other" (p. 154). Mead explains, "the attitude of the generalized other is the attitude of the entire community" (p. 154). In the baseball example, the team is the "generalized other". Mead also refers to the 
accumulated understanding of the "generalized other" (opinions, norms, social response patterns) as the "me". Through the process of teamwork, there can be a fusion of the "I" and "me" which leads to an intense emotional experience. The "I" represents the personal, self-reflective side of the individual. Through teamwork and the fusion of the "I" and "me", feelings of solidarity and group belonging can emerge. The individual will then experience a feeling of complete identification with the others in the group.

American sociologist, Herbert Blumer, is best known for his academic contributions involving symbolic interactionism. Symbolic interactionism posits that individuals typically organize their conduct in agreement with their expectations of others and depending upon their familiarity with the situation (Armstrong, 2007). The meaning of things for a person grows out of the ways in which other people act toward the person with regard to the thing. Thus, symbolic interactionism views meanings as social products, as creations that are formed in and through the defining activities of people as they interact (Blumer, 1969). Structural features, "such as culture, social systems, social stratification, or social roles, set conditions for the actions but do not determine the action" (Blumer, p. 88). Blumer's position provides for individual agency and suggests that individuals do not actually act toward culture or social structure, but rather toward situations. Social organization enters into action only to the degree to which it shapes situations and provides fixed sets of symbols which people utilize when interpreting their situations. Group activity, such as sport, is not a mere arena for expression of pre-existing factors; but rather a formative process. For some, sport participation symbolically defines the group and provides meanings that will guide and direct the future action's of the members. 
Peter M. Blau's (1964) social exchange theory is concerned with reciprocal relationships between individuals within social structures. Blau argues that social exchanges build trust over time and they are meaningful (Allan, 2007). In other words, the action has meaning and implies or signifies something beyond itself. Blau sees exchange as the starting mechanism for social interaction and group structure. Before group identities and boundaries, and before roles, status positions and norms are created; interaction is initiated in the hopes of gaining something from the exchange (Allan). Whitaker and Molstad (1985) incorporated Balu's theory into their model for examining female athletes coached by females versus female athletes coached by males. In the present study, the researchers utilize this theory to examine situations where international students participate in sport alongside American students. The activity facilitates the exchange of norms and builds trust between the two groups of participants.

Milton Gordon's (1964) Assimilation in American Life provides an excellent analysis of immigrant behavior and inter-group dynamics in the United States. Gordon discusses and critiques the concepts and rhetoric of "total assimilation", "the melting pot", and "cultural pluralism" theories. In his analysis of the nature of assimilation, Gordon provides a table that lists the forms or stages of assimilation and includes a corresponding sub-process or condition for each. One of the most common forms is cultural assimilation by substitution where the individual substitutes their heritage and behavior pattern for another (Gordon). Subordinate immigrants feel pressure to conform to the customs and behaviors of the dominant group. In the substitution model, the minority may participate little or not at all in activities with their own ethnic group. Some 
immigrants adopt a cultural pluralism model enabling them to participate in societies

major institutions (work, school, sport) while still retaining their own ethnic heritage.

Gordon examines the Anglo-Conformity ideology and indicates that this form of assimilation results in "the disappearance of the ethnic group as a separate entity and the evaporation of its distinctive values" (Gordon, 1964, p. 81). Gordon also appears to reject the notion of the "melting pot" theory and refers to it as rhetoric embedded into the American response to turn of the century immigration. He indicates that there are numerous "melting pots" or subsocieties, rather than a single American "melting pot". The theory of "cultural pluralism" is more embraced by Gordon, as he points out numerous societies within societies in the US. Immigrant groups often embrace the political and economic life, the common language, usually even the clothing of mainstream America, however; they maintain ties to their ethnic group through religious worship, holidays, meals, music, games, and other activities unique to their ancestry. Individuals belong to "primary groups, secondary groups, family groups, social cliques, associations and formal organizations, racial, religious, national origins groups, and social classes" (Gordon, p. 234). The nature of these groups and their inter-relationships has a meaningful impact upon the way in which people of diverse ethnic backgrounds regard and relate to one another (Gordon).

Immigrant Adaptation, Cultural Identity, and Sport

Stodolska and Alexandris (2004) analyzed the recreational sport participation behavior of first and one and a half generation Korean and Polish immigrants residing in Chicago and Urbana-Champaign, Illinois. Milton Gordon's (1964) seminal work, Assimilation in American Life, was incorporated into the researchers' theoretical frame. 
Gordon's assimilation model suggests that through participation in mainstream sport, immigrants adopt values and behaviors of the culturally dominant group (Stodolska \& Alexandris). The researchers conducted semi-structured in-depth interviews with 30 immigrants (19 Korean and 11 Polish). Utilizing constant comparative method for analysis, the researchers identified major themes regarding the role of recreational sport in the immigrants' adaptation. The level of involvement in recreational sports was primarily impacted by the immigrant's ethnicity and social class, but also by their gender and time spent in the United States. Typically, after the immigrants passed through their initial period of adaptation, sport participation increased. Sport activities facilitated intergroup contacts and breaking barriers between first generation immigrants, other ethnic minority members, and mainstream White Americans (Stodolska \& Alexandris). Several Polish interviewees noted that the first time they interacted with mainstream White Americans in an informal setting was during sporting activities. Some interviewees indicated that sport participation helped to solidify their ties with their ethnic community and served to facilitate the retention of ethnic identity. Stodolska and Alexandris' study showed that "participation in traditional sports strengthened community bonds and allowed Korean and Polish immigrants to socialize with individuals whom they shared common culture and experience" (p. 404).

Asian Americans are one of the fastest growing minority groups in the United States (Lee, 2005). According to the 2000 US Census, there were 1,076,872 Koreans residing in the United States. Lee conducted a study using an in-depth interview at a large Midwestern university located in an area with a growing Korean American population. All of the participants were females either born in Korea or have parents that were born 
in Korea. Results suggest that being members of the broader Asian American community impacted Korean Americans as they were heavily influenced by the dominant culture's perception of them as simply being people of Asian descent. The sporting experiences of the Korean American women in this examination often displayed a pattern of dual identity. This unsettled position in American society provided the foundation for these women to make conscious choices about the sports in which they selected for participation. A lacrosse player seems to have selected her sport as a symbolic expression of her rejection of Asian American stereotypes. Other participants indicated that they saw Tae Kwon Do, a traditional Korean martial art, as a vehicle for strengthening ties to their ethnic background and expressed pride in their culture. Another participant explained that she joined a dance sport team as a means for assimilating into the dominant society. The dance team enabled her to come into contact with non-Korean Americans and become more outgoing and socially aware.

Bachay's (1998) study examined the effects of a preventative, psycho educational, counselor intervention on the ethnic identity development of urban Haitian adolescents in the United States. Bachay (1998) asserts that newly arrived immigrants to the United States are not socialized to the behaviors of the dominant culture, thus, they may experience feelings of anxiety, confusion, fear, helplessness, and homesickness. An individual's ethnic identity development is entangled with an individual's perception of group belonging. Through years of counseling Haitian youth, the researcher discovered that rejection of the Haitian immigrant youth by dominant culture and minority peers compels Haitian youth to consistently distance themselves from their own culture. In order to disown their heritage, Haitian youth reject their native language, foods, games, 
and sports as well as religious and cultural expressions that might reveal evidence of their Haitian culture. It is interesting that soccer clubs remain a popular activity for Haitian adult males in South Florida, but the sport is losing appeal among Haitian youth there. Many Haitian-American youth have adopted American football as their sport in order to develop a new identity and gain acceptance from their peers. Bachay concludes that the pressure to conform and assimilate into American culture can have a profound impact on the sporting behavior of immigrant groups.

Modern sports "constitute one of the numerous forms of culture which provide a vehicle for meaningful expression and communication" (Giossos, 2008, p. 53). Sport participation serves as the identity bearer while at the same time contributing to the construction and reproduction of a significant part of an individual's identity (Giossos). Giossos examined the social conditions under which refuges founded a soccer club in the Greek city of Volos in the early 1920s. Newspapers and archival documents were examined and personal interviews were conducted in order to investigate the topic. Shortly after the end of World War I, the allied forces created the country of Turkey. However, Greece continued its military operations in Asia Minor, but in 1922 the Turks counter-attacked and managed to remove the Greek military from their lands. As a result, tens of thousands of Greeks sought refuge in mainland Greece. The first establishment of a soccer team by these refugees was in 1923 in the city of Volos. The soccer team held great importance for the refugees and one archival source explains that the only things the refugees took with them when they relocated was the icon of Mother Mary from their church and their soccer team. The team adopted a black and yellow color scheme in order to emphasize their Byzantine cultural background. A network of social relationships 
within the refugee community was emphasized and it was important that new members did not come in and alter the uniformity of the team. Players from the team enjoyed status and respect in the community and the team was responsible for the preservation of their unique cultural identity. Sport consumption can serve as a vehicle for international students to preserve their cultural identity. International Students and Physical Activity

Yoh, Yang, and Gordon (2008) examined the frequency of participation in physical activity among international students attending American universities. The researchers obtained a sample of 521 international students from five different universities in the Midwest. On average, the international students participating in this study spent 3.4 hours participating in physical activities per week. The operational definition of physical activity used in their study encompassed a wide spectrum, ranging from competitive and structured events to any informal or unstructured form of exercise, sport, or recreation not associated with one's job duties. Results from the questionnaire revealed that students from North America (i.e., Canada and Mexico) participated in physical activity the most. This group was followed closely by students from Europe and then students from South America. Students from Asian and African countries spent significantly less time participating in physical activities than international students from other continents. When examining the interaction between gender and origin of the international students, females from Asian countries spent significantly less time participating in physical activities than any other group.

Li and Stodolska (2006) examined Chinese international graduate students in order to identify factors relating to their transnational status that might impact their 
leisure behavior. The theory of transnationalism asserts that modern day migrants maintain social, cultural, political, and economic affiliations with their nation of origin while studying or working abroad (Li \& Stodolska). The researchers conducted interviews with 16 Chinese graduate students attending the University of Illinois at Urbana-Champaign. The researchers identified three central themes regarding the relationship between transnationalism and leisure behavior. First, the temporary status of the Chinese graduate students impacted their leisure behavior. Students explained that they were attending an American university primarily to focus on their studies and research, thus improving their career opportunities when they return home. The academic priorities of the participants suggest that there was virtually no time for leisure. Second, the emotional status of the Chinese graduate students impacted their leisure behavior. Many felt that their time constraints and academic pressures spilled over into their free time resulting in a prevalent displeasure with life. The students expressed that they were psychologically consumed by their work which prevented them from enjoying any leisure opportunities that they had. Third, the legal status and travel situations impacted their leisure behavior. Strict visa requirements and an inability to take pleasurable trips forced the subjects to defer leisure activities until after their degrees were completed. However, the studies conducted by Yoh, Yang, and Gordon (2008) and Li and Stodolska (2006) did not concentrate specifically on recreational sport participation, thus demonstrating the need for the current examination.

\section{Previous Scales Measuring Cultural Identity}

The importance of examining ethnic variables and their impact on consumption behavior is supported by the global, multicultural context found in numerous 
industrialized countries (Pons, Laroche, Nyeck, \& Perreault, 2001). Sport and sporting events are recognized as having a key relationship with the values and culture of many countries and they signify important meanings for individuals (Pons et al). Pons et al. developed a scale to assess the linkage between ethnic variables and sport consumption as well as asses the social role that sport plays in multi-cultural societies with regards to immigrant adaptation. Utilizing a cultural pluralist approach, Pons et al. examined the relationship between soccer and the Italian Canadian community in Montreal and the relationship between hockey and the French Canadians located in Quebec City. Their questionnaire included three measurement scales representing the constructs of acculturation (ACC), ethnic identity (EI), and orientation toward sporting events (OSE). Their acculturation construct was based on the bi-level assimilation model. Their ethnic identity construct included three factors; language use with family, interaction and social involvement in the subject's ethnic community, and religious affiliation. The orientation toward sport events construct considered three dimensions; the role of sporting events as a provider of sensations, the capacity of sporting events to fulfill particular cognitive needs, and the socialization properties of sporting events. There were 37 items under three constructs measured on a 5-point Likert scale. The orientation toward soccer and hockey was measured for each subject. The instrument also measured other behaviors associated with sport consumption such as purchasing patterns and time spent at sporting events. The reliability coefficients (Cronbach's alphas) were assessed for the instrument and all the dimensions were above the .8 threshold for acceptance.

Results from the study revealed that French Canadian respondents were more oriented toward hockey while Italian Canadians were oriented toward soccer. 
Additionally, ethnic identity was positively related to soccer consumption and acculturation was positively related to hockey consumption. Data obtained through their instrument supported this hypothesis by indicating that highly acculturated Italian Canadian hockey fans shared a similar orientation profile to that of French Canadians. At the same time, highly acculturated Italian Canadian soccer fans shared similar orientation profile to that of their less acculturated Italian Canadian peers (Pons et al., 2001).

Harrolle and Trail (2007) examined the structural relationship among ethnic identity, acculturation, identification with specific sports, and identification with sports in general for Latinos residing in the United States. Mead's identity theory (1934) was incorporated into their theoretical frame. Data were collected from 373 Latino participants at various locations including Latino restaurants, doctors' waiting rooms, and a Latino outdoor music festival. The researchers utilized three existing scales when developing their instrument. First, Roberts et al.'s (1999) version of the Multigroup Ethnic Identity Measure (MEIM) was incorporated in order to understand ethnic identity across their sample. Second, Zea et al.'s (2003) Abbreviated Multidimensional Acculturation Scale was utilized to measure identity, language competence and cultural competence. Third, Robinson and Trail's (2005) Point of Attachment Index (PAI) was adopted to measure how attached the subject was to a specific sport and to sport in general. The final version of their instrument contained 27 items randomly placed on the questionnaire on a 7-point Likert scale.

Structural Equation Modeling (SEM) was utilized to test the confirmatory factor analysis of the total measurement model (CFA). Results of the CFA indicated a close fit and the Cronbach's alpha reliability coefficients were good for all constructs in all three 
scales ranging from 80 to .94 . They then tested four proposed models that were based on findings from previous researchers in various settings. All four models used fit the data well. The results of the study indicated that the majority of Latinos participating in the study were highly acculturated with the dominant US society. Acculturation had a small influence on the subject's identification with American football, baseball, basketball and sport in general. Also, as the ethnic identity of Latinos increased, their identification with hockey decreased. Interestingly, even when levels of ethnic identity and acculturation varied, attachment to soccer remained the same. The researchers concluded that for Latinos as a whole, ethnic identity and acculturation had a greater impact on their identification with American football than for all the other sports examined.

Based on the review of literature and pursuant to the exploratory nature of this study, the researchers sought to develop a better understanding of international students' sport participation behavior by advancing the following research questions:

Research Question 1: Will the international students' nationality impact their behavior with regards to participating with individuals from the same cultural background or with individuals from a different cultural background?

Research Question 2: Will the international students' nationality impact their intention to utilize sport as a vehicle for assimilating into their new cultural environment or as a vehicle for maintaining the cultural identity associated with their heritage?

Research Question 3: Will there be a significant relationship between nationality and the particular sport(s) that international students most frequently participate in?

Research Question 4: Will the length of time that the international students have been living in the United States significantly impact the frequency of their participation? 
Research Question 5: Will the length of time spent living in the United States impact the international student's sport participation behavior with regards to utilizing sport as a vehicle for assimilation or as a vehicle for maintaining cultural identity?

Research Question 6: Will the international students' gender impact their sport participation behavior with regards to utilizing sport as a vehicle for assimilation or as a vehicle for maintaining cultural identity?

\section{Methods}

\section{Participants}

The sample was recruited from international students attending two universities located in the South, one located in the Mid-West, and one located in the West that voluntarily responded to an online survey distributed to them via their universities' international studies department. However, varsity athletes participating in intercollegiate sports were requested not to respond to the online survey. Written permission from the university's international studies office and Institutional Review Board (IRB) approval was obtained. These four universities were selected because they are large comprehensive universities with undergraduate, masters, and doctoral students, thus providing a representative sample of students from a variety of degree programs. Also, the universities in this study are located in different geographic regions in the United States, allowing the researchers to obtain a more representative sample. Furthermore, the universities in this study were very enthusiastic about the research topic and indicated that the data obtained would provide useful information for their international studies office as well as their campus recreation department. 
As a result, a total of 242 responses were collected. Of those, 240 surveys were found to be useable, with two being discarded due to having too many missing values. Of the 240 participants, 133 were males $(55.4 \%)$ and 107 were females $(44.6 \%)$. Approximately, 36\% were from Asian nations (eg. China, Japan, Korea), 25\% were from South Asian nations (eg. India, Pakistan, Bangladesh), 11\% were from European nations (eg. Germany, France, Spain), 10\% were from either the United Kingdom, Australia, or Canada, 9\% were from Latin American nations (eg. Brazil, Mexico, Dominican Republic), 5\% were from Middle Eastern nations (eg. Syria, Saudi Arabia, Egypt), and 4\% were from African nations (eg. Nigeria, Kenya, Cameroon). Approximately, 30\% of the international students had been living in the United States for 1 year or less, $23 \%$ had been living in the US for more than 1 year and less than $2,18 \%$ had been living in the US between 2 and 3 years, and 29\% had been living in the US for more than 3 years.

\section{Instrument}

One of the purposes of the current study was to develop a scale for measuring socialization, cultural maintenance, and assimilation through sport. For the current study, a total of four dimensions that consisted of 24 items were conceptualized following the literature review: 1) participate with same cultural background (6 items), 2) participate with different cultural background (6 items), 3) participate to retain cultural identity (6 items), and 4) participate to assimilate into new culture (6 items). The 'participate with same cultural background' construct was supported by Durkheim's (1960) theories of social solidarity and Mead's (1934) identity theory. The "participate with different cultural background' construct was supported by Blau's (1964) social exchange theory. The 'participate to retain cultural identity' construct was supported by Blumer's (1969) 
theory of symbolic interactionism. The 'assimilate into new culture' construct was supported by Gordon's theory of assimilation and sub-processes (1964). The 4-point scale was adopted that included the following points: $1=$ Totally Untrue, $2=$ Somewhat Untrue, $3=$ Somewhat True, $4=$ Totally True, Unsure $=0$. Zero was treated as a missing value.

Frequency of participation was measured by the number of times that the respondent physically engaged in sport per month. Sport selection instructed the respondent to rank their top three sports based on frequency of participation. There were sixteen different sports to select from and there was the option of 'other' for respondents that frequently participated in a non-listed sport. For the purpose of sampling description, various demographic variables were included in the questionnaire, which consisted of age, nationality, gender, and length of time spent living in the United States.

\section{Procedures}

Following the development of the initial instrument, it was submitted to a panel of eight experts in the field of sport sociology, sport management, leisure, recreation, and measurement. The panel of experts evaluated the face and content validity of the entire instrument. After receiving feedback from the panel of experts, necessary adjustments were adopted and a focus group was conducted with four English Learning Institute students from one of the universities participating in the study. The purpose of the focus group was to ensure that the items would be fully comprehended by students for whom English is a second language. Based on the feedback from the focus group, the wording of the initial questionnaire was modified until it was determined to be completely 
understood by all members of the focus group. The instrument was again reviewed by the expert panel and was supported.

As previously stated, international students participated in this study by responding to an e-mail message which contained a link to the online version of the survey. All international students with a registered e-mail address attending the four universities participating in the study received a message notifying them of the study through the international studies office at their respective universities. Respondents completed the survey online and the data were transferred directly to a file that only the researchers had access to. A total of 2935 international students were e-mailed a link to the survey and a total of 242 returned a survey, representing a return rate of $8.2 \%$. However, since not all international students participate in sport, the instrument is only relevant to a portion of the students e-mailed. Thus, the true response rate is impossible to calculate.

\section{Data Analyses}

Using SPSS version 16.0 (SPSS, 2007), descriptive statistics were calculated for the sport participation factors and socio-demographic variables. Because the factors and items in the Sport and Cultural Identity Scale (SCIS) were created by the researchers of the current study based on four sociological theories and empirical findings on cultural identity and socialization, an exploratory factor analysis (EFA) was deemed necessary as the analytical step to examine the factor structure of the measure. The main purpose of the EFA was to identify a unique and reliable simple factor structure that was of the potential to be generalized to a universe of variables from a sample of variables. In the EFA, principal axis factoring extraction; followed by oblimin rotation method were 
applied. This is the preferred approach when proposed factors are correlated (Hair, Black, Babin, Anderson, \& Tatham, 2005). The following criteria were employed to determine the factors and their items: (a) an item had a factor loading equal to or greater than .40 (Nunnally \& Bernstein, 1994), (b) parallel analysis (Hayton, Allen, \& Scarpello, 2004), (c) a scree plot (Cattell, 1966), and (d) an identified factor and retained items must be interpretable in the theoretical context. Cronbach's alpha $(\alpha)$ values were also calculated to measure the reliability of the participation scale. The recommended .70 cut-off value was adopted to determine internal consistency.

In order to determine if there was a significant relationship between nationality and participation behavior, a MANOVA was conducted with the derived factors serving as dependent variables in the model. A chi-square test was conducted to determine if there was a significant relationship between nationality and sport preference. A Pearson bivariate correlation test was utilized to determine if there was a significant relationship between the length of time the individual had lived in the US and their frequency of participation. Additionally, Pearson bivariate correlation tests were used to determine if there was a significant relationship between the length of time the individual had lived in the US and participation behavior with regards to assimilation and maintaining cultural identity. Lastly, a MANOVA was conducted to determine if gender impacted participation behavior with regards to assimilation and maintaining cultural identity.

Results

Principal axis factoring was initially conducted using an oblimin rotation method. Item correlations ranged from -.52 to .47 . The Kaiser-Meyer Olkin measure of sampling adequacy was .90 , which was a more than acceptable value to proceed with the analysis 
(Kaiser \& Rice, 1974). When conducting the exploratory factor analysis, the initial solution retained five factors based on the criteria of eigenvalues greater than 1. According to Stevens (2002), the number of factors to retain, however; is more appropriately determined by the scree plot and parallel analysis (Zwick \& Velicer, 1986). The scree plot suggested a three factor solution, however; after running a parallel analysis, it appeared that a two-factor solution would be more appropriate. Parallel analysis allowed the researchers to compare the results obtained from analyzing random data with that of the data collected from the study. The next step was to examine the factor loading of the individual items. It was determined that four items needed to be removed from the analysis. Two of these items did not load on a single factor, one item loaded with a factor that did not make theoretical sense, and another item double loaded.

Principal axis factoring with oblimin rotation method was rerun with the retained items (Table 1). This time the scree plot suggested that two factors be extracted, which was supported by the parallel analysis. The Kaiser-Meyer Olkin measure of sampling adequacy was .89 , which was more than acceptable for continuing with the analysis. The researchers were confident utilizing the two factor solution for further analysis, which explained $51 \%$ of the variance. The two factors were a) cultural maintenance and b) cultural assimilation. Essentially the 'participate to retain cultural identity' and 'participate with same cultural background' constructs were combined into one factor, being labeled as cultural maintenance (10 items) while the 'assimilate into new culture' and 'participate with different cultural background' constructs were combined into the other factor, named cultural assimilation (10 items). The researchers then assessed the Cronbach's alpha coefficients for determining the reliability of the two factors. The alpha 
coefficient was .87 for the ten-item cultural maintenance subscale, which is above the common benchmark for score reliability (Kline, 1991). The alpha coefficient was .89 for the ten-item cultural assimilation subscale, well above the suggested criteria for determining reliability.

Before examining the results of a MANOVA test, the researchers conducted a series of assumption tests to see if the data were appropriate for MANOVA test (Hair et al., 2005). The assumption tests included: (a) independence of observations, (b) homoscedasticity, (c) equality of variance-covariance matrices, and (d) normality. The only violation occurred during the second assumption test. As a result of Levene's test for the two dependent variables, the cultural maintenance variable resulted in a nonsignificant value $(p>.05)$; indicating equal variances were placed for across the variable. However, the cultural maintenance variable showed a significant value $(p<.05)$, thus violating the assumption. Considering that MANOVA is robust to violations of homoscedasticity, the researchers preceded with the analysis (Hair et al.). As a result of the MANOVA test, the Wilks' Lambda indicated that there was not a statistically significant difference of the two dependent variables across nationality, $F(12,368)=$ $1.21,(p>.05)$. Descriptive statistics revealed that opportunities for cultural assimilation through sport were more important than cultural maintenance through sport, regardless of nationality. The mean score for cultural assimilation was $2.9(S D=.75)$, while the mean score for cultural maintenance was $2.6(S D=.75)$.

Before examining the results of the chi-square test, a series of assumption tests were performed. The assumption tests included: a) having two categorical variables, b) independence of observation, and c) at least five samples in all cells. There were no 
violations of these assumptions. Results of the chi-square test indicate there was a statistically significant relationship between the international students' nationality and the specific sports that they most frequently participate in $(p<.01)$. Inspection of the cross tabulation table allowed the researchers to recognize the sport selection preferences of each nationality group (Table 2). International students from Asian nations most frequently participated in badminton, while South Asians most frequently participated in cricket. International students from Latin American, European, and African nations participated in soccer more than any other sport. The international students from the United Kingdom, Canada, and Australia were more diversified in their sport participation. While running and track and field had the highest participation frequency, this was followed closely by basketball, baseball/softball, and golf. Students from Middle-Eastern nations also appeared to be more diversified. While swimming had the highest participation frequency, this was followed closely by tennis and soccer.

The researchers then examined the Pearson correlation statistic for the relationship between the length of time spent living in the United States and the international students' frequency of sport participation. Before examining the results of the Pearson correlation test, a series of assumption tests were conducted. The assumption tests included: a) mean of $\mathrm{Y}$ is related to $\mathrm{X}$ by the linear equation, b) the conditional standard deviation is identical at each X-value, c) independence of observations, and d) normality. The researchers identified that all of these assumptions were met and preceded with the analysis. The Pearson correlation statistic was non-significant, $(p>.05)$. Therefore, there was not a significant relationship between these variables among the international students participating in the present study. Next, the researchers examined the Pearson 
correlation statistic for the relationship between length of time spent living in the United States and the cultural maintenance variable. Again, the Pearson correlation statistic was non-significant, $(p>.05)$. The researchers were unable to find a significant relationship between time spent living in the US and cultural maintenance through sport. Furthermore, the Pearson correlation statistic for the relationship between time spent living in the US and cultural assimilation through sport was non-significant, $(p>.05)$.

Before examining the results of the second MANOVA test, the researchers conducted a series of assumption tests to see if the data were appropriate for MANOVA testing. The assumption tests included: (a) independence of observations, (b) homoscedasticity, (c) equality of variance-covariance matrices, and (d) normality. Hair et al. (2005) argued that the independence of the data could be ensured by random sampling. The researchers obtained independent observations by e-mailing a link to the survey to all of the international students attending the universities participating in the study. The second assumption test was conducted using Levene's test for the two dependent variables. As a result, both dependent variables showed non-significant values $(p>.05)$; indicating equal variances were placed for both of the dependent variables. For the third assumption test, Box's M was non-significant $(p>.05)$. Therefore, there was not a substantial difference in the amount of variance of one group versus another for the dependent variables. The assumption of normality for the dependent variables was examined by means of skewness and kurtosis values, which showed that all the values were within acceptable threshold, ranging from -.85 to 2.2 (Chou \& Bentler, 1995). Finally, a boxplot was utilized to examine potential outliers. Examining the boxplot showed that there were no extreme points for the two groups. Based on a series of 
assumption tests related to MANOVA, it was determined that the current data met all the assumption tests.

As a result of MANOVA test, the Wilks' Lambda indicated that there was a statistically significant difference of the two dependent variables across gender, $F(2$, $188)=3.43,(p<.05)$. A Bonferroni correction was used to account for the two separate hypotheses being tested. Examination of the tests of between-subjects effects revealed that gender significantly impacted the cultural maintenance variable $(p<.025)$ and did not significantly impact the cultural assimilation variable $(p>.025)$. Inspection of the means indicated that males scored higher in the cultural maintenance variable $(M=2.71$, $S D=.69)$ than females $(M=2.44, S D=.81)$.

Due to the exploratory nature of this study, the researchers were interested in determining if there was a significant relationship between the two derived factors; cultural maintenance and cultural assimilation, and frequency of participation. Two Pearson correlation tests were performed in order to examine these relationships. Results indicated that the international students' score on the cultural assimilation variable had a significant relationship with their frequency of participation $(p<.05)$. The means revealed that international students that participated in sport between 4 and 8 times per month were associated with the highest cultural assimilation scores. The results of the second Pearson correlation test indicated that there was not a significant relationship between cultural maintenance and frequency of participation $(p>.05)$.

\section{Discussion}

Empirical examinations of sport participation behavior among international students in the United States are meager (Li \& Stodolska, 2006; Yoh, Yang, \& Gordon, 
2008). In fact, the previous studies examined physical activity and leisure behavior, rather than specifically targeting sport participation. Seeking to better understand this area and fill in research gaps, the current study was designed to examine international students' sport participation behavior with regards to maintenance of cultural identity and assimilation. While previous researchers (Giossos, 2008; Lee, 2005; Stodolska \& Alexandris, 2004) indicate that sport provides opportunities for immigrants to maintain their cultural identity or to assimilate into a new culture, researchers have strictly employed qualitative methods when examining this relationship. The current study utilizes a quantitative approach which is grounded by well established sociological theories.

Appropriate scale development techniques were incorporated in order to examine the relationship between various demographic variables and the cultural maintenance and assimilation factors. Results indicate that the factors included in the current model were valid and reliable measures of sport participation behavior among international students in the United States. While the researchers originally hypothesized that there could be four factors, it makes logical sense that these four factors should be reduced to a two factor model. The cultural maintenance factor is supported by solidarity, identity, and symbolic interactionism theories. All of the items retained in this factor relate to cultural maintenance. The cultural assimilation factor is supported by social exchange and assimilation theories. All of the items in this factor are relevant to cultural assimilation. Based on the obtained means, cultural assimilation through sport appears to be more important to the international students in this study than opportunities for cultural maintenance through sport. However, there was a significant relationship between gender 
and the cultural maintenance factor. Males reported higher scores in the cultural maintenance factor than females. While there is no previous literature that could aid in the explanation of this finding, it is an important addition to the present body of knowledge. Significant gender differences in sport behavior allow sport managers to more effectively target their audience and develop segmentation strategies. Emphasizing opportunities for cultural maintenance through sport may attract more male consumers to the sport product.

Results from Stodolska and Alexandris' (2004) qualitative study indicated that the length of time that an immigrant has lived in the United States impacts their frequency of their sport participation. The researchers in the current study were unable to detect a significant relationship between length of time living in the United States and sport participation frequency among international students. Additionally, the length of time spent living in the US did not impact the international student's sport participation behavior with regards to utilizing sport as a vehicle for assimilation or as a vehicle for maintaining cultural identity. The researchers in the present study were able to detect a significant relationship between frequency of participation and the cultural assimilation variable. International students that physically participated in sport between four and eight times per month scored higher in the cultural assimilation factor than those that participated zero to three times per month, nine to fifteen times per month, and sixteen to thirty times per month. This statistical finding helps us to better describe the international students that utilize sport as a vehicle for assimilation.

The current study was able to detect a significant relationship between nationality and sport preference. Inspection of the cross tabulation table allowed the researchers to 
recognize the sport selection preferences of each nationality group. International students from Latin American, European, and African nations participated in soccer more than any other sport. International students from Asian nations most frequently participated in badminton, while South Asians most frequently participated in cricket. The international students from the United Kingdom, Canada, and Australia were more diversified in their sport participation. Running and track and field had the highest participation frequency, however; this was followed closely by basketball, baseball/softball, and golf. Students from Middle-Eastern nations were also more diversified in their participation. Swimming had the highest participation frequency, but this was followed closely by tennis and soccer. Examinations conducted by previous researchers (Stodolska \& Alexandris, 2004) emphasize the relationship between cultural identity and sport participation. Results from the current study allow us to identify the sports that are most frequently participated in by each nationality group; thus allowing us to enhance our understanding of cultural identity and sport participation.

\section{Implications for Sport Managers}

Previous researchers have indicated that sport participation provides individuals with opportunities for attaining social capital (Light \& Kirk, 2001). While this can be a beneficial situation for some, sport is also serving as a powerful mechanism for exclusion and elitism (Majumdar, 2003). Those that do not have adequate opportunities for sport participation may have less access to valuable social capital. It is essential that sport managers remove barriers preventing sport participation and promote cultural diversity. It is critical for individuals involved in the programming of campus recreational sport to examine the results from the current study. International students participating in the 
study emphasized cultural assimilation through sport over cultural maintenance through sport. However, if these students are not provided appropriate opportunities for participation and inclusion; assimilation may be limited. Individuals involved in the programming of campus recreational sport that recognize these assimilation desires can provide programming, special events, and promotional activities that may enhance the adaptation process for international students.

Results from the current study indicate that there is a significant relationship between nationality and sport selection. This allows American universities to identify which sports are most frequently participated in by the various nationality groups. Sports that are not traditionally popular in the United States may receive limited funding, access to facilities, and scheduling from the university. Results from the current study indicate that international students from Asian nations such as China most frequently participate in badminton while students from South Asian nations such as India most frequently participate in cricket. Since these sports are not traditionally popular in the US, some university campuses may be providing little or no opportunity for these activities. However, with the international student population on the rise, it is critical that campus recreation department provide resources for the programming of these sports. Also, efforts must be made to encourage American students to participate in sports like badminton and cricket alongside the international students. This will provide excellent opportunities for integration, inclusion, and social exchange.

Results from the study indicate that soccer, the world's most popular sport, is the primary participation sport for the international students from Latin American, European, and African nations. While soccer is not one of the most popular spectator sports in the 
United States, participation is relatively high. Campus recreation departments typically offer adequate resources for soccer participation. The researchers recommend that universities utilize their soccer programming to promote cultural diversity and exchange on campus. Leagues and tournaments can be organized in such a way that they emphasize the global appeal of the game while at the same time fostering the American integration philosophy. International students from the United Kingdom, Canada, Australia, and Middle-Eastern nations appeared to be much more diversified in their participation. Also, they appear to be participating in sports that are at least moderately popular in the US. Considering that they are participating in a wide variety of sports which are typically programmed sufficiently by campus recreation departments; programming for this segment may be similar to the programming strategies and techniques used for the American student. The only additional consideration would be the emphasis on inclusion and cultural exchange by the campus recreation department.

Sport managers should also take note of the significant gender difference that was detected with regard to cultural maintenance through sport. Males indicated that they found cultural maintenance through sport to be more important than the females participating in this study. The assimilation factor resulted in a higher mean score regardless of gender, however; sport can provide powerful opportunities for cultural maintenance. Campus recreation departments should take note that males had higher cultural maintenance scores than the females. While some international students utilize sport to assimilate into their new environment, others will be participating to retain a sense of their cultural heritage. For these individuals, sport serves as a point of attachment facilitating group solidarity and fosters cultural identity. Chinese students 
participating in badminton, Indian student participating in cricket, Brazilian students participating in soccer, all have the opportunity to engage in a familiar activity and express their cultural identity. Arriving on an American campus can be an overwhelming and stressful experience for international students. Sport participation can provide them with an opportunity to socialize with others that share their same cultural background. This will allow them to feel more at home and help them adapt to their new environment. Numerous studies from previous researchers (Giossos, 2008; Stodolska \& Alexandris, 2004) have examined the relationship between cultural identity and sport; however none have used statistical methods to reveal the impact of gender on this relationship. Results from the current study provide practitioners of recreational sport on college campuses with strategies for segmenting international students based on gender. It may prove fruitful to emphasize and promote the cultural heritage and affiliation elements of sport to male international students. Conversely, it may be beneficial to promote opportunities for cultural assimilation through sport to female international student.

The researchers understand the financial limitations that campus recreation departments' experience, therefore, the expansion of sport programming for international students may not be realistic for all universities. However, universities with a substantial percentage (over 10\%) of their student population consisting of international students are encouraged to consider expansion and inclusion strategies. The international student pays student activity fees just as the American student does and deserves sport programming that meets their cultural needs. 
Limitations and Future Research

One of the limitations to this study was the use of only four universities during one semester of enrollment for soliciting responses from international students. A follow up study should be conducted in order to further explore sport participation behavior among international students attending American universities. Different universities should be targeted for participation in order to better generalize the results. In fact, there were no universities from the Northeastern United States or from the West Coast. American universities from these regions should be contacted in an attempt to gain a more representative sample.

Another limitation of the study relates to the development of an entirely new scale. Initially the researchers hypothesized that there could be as many as four separate factors, however; the researchers appear to be measuring two. These two factors are cultural maintenance and cultural assimilation. For the follow up study, the researchers should be able to better measure these factors by revising the initial scale. The four items that were removed from the analysis will be deleted from the instrument. Meanwhile, the research findings on content validity and convergent validity needed to be improved. Although the panel members for the test of content validity included academicians who had expertise on sociology, sport management, and measurement, initially proposed items and factors in the preliminary scale had to be excluded or combined from the final version of the scale, suggesting that discrepancies existed between the expert panel and actual data obtained from the research participant. Future studies should consider applying a more rigorous approach of testing content validity outlined by Aiken (1996) and Dunn, Bouffard, and Rogers (1999). In this contemporary approach, item 
examinations by the panel members are focused on the constructs. The three aspects of content validity (i.e., relevance, representativeness, and clarity) are simultaneously evaluated through various statistical procedures, including content validity coefficient, rater homogeneity coefficient, and rater reliability coefficient. Via this process, discrepant raters can be obtained and weak and double loadings can be also determined, which may lead to improved content validity. In future attempt, the researchers should employ confirmatory factor analysis (CFA) to test various models, including four-factor model, two-factor model to see if which model shows better stability.

Furthermore, the researchers neglected to measure the impact of social class on sport participation behavior. Stodolska and Alexandris (2004) indicate that an immigrant's social class impacts their sport participation behavior with regards to cultural maintenance and assimilation. This idea is also supported by Milton Gordon's (1964) theoretical framework. Traditionally, college students are limited in their ability to earn income while in school. Nevertheless, the social class in which they originally come from may have a significant impact on their sport participation behavior. While it may be difficult to obtain social class information from the student participants, it is quite possible that this variable accounts for some of the unexplained variance in our model.

\section{Conclusion}

Sport participation provides international students with paths for both maintaining cultural identity and assimilating into a new culture. It is essential for practitioners involved in the programming of recreational sport on college campuses to understand this phenomenon as well as the relationship between nationality and sport participation. This will enable universities to more effectively serve the needs of international students. 


\section{References}

Aiken, L. R. (1996). Rating scales and checklists: Evaluating behavior, personality, and attitude. New York: Wiley.

Allan, K. (2007). The social lens: An invitation to social and sociological theory. Thousand Oaks, CA: Sage.

Armstrong, K. L. (2007). Self, situations, and sport consumption: An exploratory study of symbolic interactionism. Journal of Sport Behavior, 30, 111-129.

Bachay, J. (1998). Ethnic identity development and urban Haitian adolescents. Journal of Multicultural Counseling and Development, 26, 96-109.

Blau, P. M. (1964). Exchange and power in social life. New York: Wiley.

Blumer, H. (1969). Symbolic interactionism: Perspective and method. Englewood Cliffs, NJ: Prentice Hall.

Cattell, R. B. (1966). The scree test for the number of factors. Multivariate Behavioral Research, 1, 245-276.

Chou, C. P., \& Bentler, P. M. (1995). Estimates and tests in structural equation modeling. In R. H. Hoyle (Ed.), Structural equation modeling: Concepts, issues and applications (pp. 37-55). Thousand Oaks, CA: Sage.

Dunn, J. G., Bouffard, M., \& Rogers, W. T. (1999). Assessing item content-relevance in sport psychology scale construction research: Issues and recommendations. Measurement in Physical Education and Exercise Science, 3, 15-36.

Durkheim, E. (1972). Restitutive sanctions and the relationship between mechanical and organic solidarity. In A. Giddens (Ed.), Selected Writings, (pp. 135-140). London: Cambridge University Press. (Original work published 1960) 
Eitzen, S. D., \& Sage, G. H. (2003). Sociology of North American Sport. New York: McGraw-Hill.

Giossos, Y. (2008). Scoring for the homeland: The soccer team of the refugees of Volos. Studies in Physical Culture and Tourism, 15, 53-63.

Gordon, M. M. (1964). Assimilation in American life: the role of race, religions and national origins. New York: Oxford University Press.

Hair, J. F., Black, W. C., Babin, B. J., Anderson, R. E., \& Tatham, R. L. (2005). Multivariate data analysis (6th ed.). Upper Saddle River, NJ: Prentice Hall.

Harrolle, M. G., \& Trail, G. T. (2007). Ethnic identification, acculturation and sports identification of Latinos in the United States. International Journal of Sports Marketing \& Sponsorship, 8, 234-253.

Hayton, J. C., Allen, D. G., \& Scarpello, V. (2004). Factor retention decisions in exploratory factor analysis: A tutorial on parallel analysis. Organizational Research Methods, 7, 191-205.

Hochschild, J. P. (2006). Globalization: Ancient and modern. Intercollegiate Review, $41,40-48$.

Institute of International Education, Open Doors (2008). International students on U.S. campuses at all-time high. Retrieved May 9, 2009, from http://www.iie.org/

Kaiser, H. F., \& Rice, J. (1974). Little Jiffy, Mark IV. Educational and Psychological Measurements, 34, 111-117.

Kline, P. (1991). Intelligence: The psychometric view. London: Routledge.

Lee, Y. (2005). A new voice: Korean American women in sports. International Review for the Sociology of Sport, 40, 481-495. 
Li, M., \& Stodolska, M. (2006). Transnationalism, leisure, and Chinese graduate students in the United States. Leisure Sciences, 28, 39-55.

Light, R., \& Kirk, D. (2001). Australian cultural capital-rugby's social meaning: Physical assets, social advantage and independent schools. Culture, Sport, \& Society, 4, 81-98.

Majumdar, B. (2003). Cricket in India: Representative playing field to restrictive preserve. Culture, Sport, \& Society, 6, 169-189.

Mead, G. H. (1934). Mind, self, \& society. Chicago: University of Chicago Press.

Mizruchi, M. S. (1985). Local sports teams celebration of community: A comparative analysis of the home advantage. Sociological Quarterly, 26, 507-518.

Nunnally, J. C., \& Bernstein, I. H. (1994). Psychometric theory (3 ${ }^{\text {rd }}$ ed.). New York: McGraw-Hill.

Pons, F., Laroche, M., Nyeck, S., \& Perreault, S. (2001). Role of sporting events as ethnoculture's emblems: Impact of acculturation and ethnic identity on consumers' orientation toward sporting events. Sport Marketing Quarterly, 10, $231-240$.

Stevens, J. P. (2002). Applied Multivariate statistics for the social sciences (4th ed.). Hillsdale, NJ: Erlbaum.

Stodolska, M., \& Alexandris, K. (2004). The role of recreational sport in the adaptation of first generation immigrants in the United States. Journal of Leisure Research, $36,379-413$.

Washington, R. E., \& Karen, D. (2001). Sport and Society. Annual Review of Sociology, 27, 187-212. 
Whitaker, G., \& Molstad, S. (1985). Male coach/female coach: A theoretical analysis of the female sport experience. Journal of Sport \& Social Issues, 9, 14-25.

Weiss, O. (2001). Identity reinforcement in sport. International Review for the Sociology of Sport, 36, 393-405.

Yoh, T., Yang, H., \& Gordon, B. (2008). Status of participation in physical activities among international students attending colleges and universities in the United States. College Student Journal, 42, 1110-1117.

Zea, M. C., Asner-Self, K. K., Birman, D., \& Buki, L. P. (2003). The abbreviated multidimensional acculturation scale: empirical validation with two Latino/Latina samples. Cultural Diversity and Ethnic Minority Psychology, 9(2), 107-126.

Zwick, W. R., \& Velicer, W. F. (1986). Comparison of five rules for determining the number of components to retain. Psychological Bulletin, 99, 432-442. 


\title{
CHAPTER V \\ MANUSCRIPT TWO \\ INTERNATIONAL STUDENTS' SPORT SPECTATORSHIP AND MEDIA CONSUMPTION
}

\author{
James T. Allen
}

The University of Southern Mississippi

Will be submitted to: Journal of Contemporary Athletics

Date of Submission: July 2009 


\section{Introduction}

One of the results of globalization has been an increase in the number of foreign nationals seeking educational opportunities in the United States (Yoh, Yang, \& Gordon, 2008). College campuses across the US benefit from a constant arrival of international students. According to the Institute of International Education (2008), there were 623,805 international students enrolled at American universities for the 2007-2008 academic year (n.p.). Sport consumption can be utilized by international students in a variety of ways. For some, sport spectatorship provides opportunities for social networking. These networking opportunities may allow the international students to assimilate into their new cultural environment. Others may utilize their sport consumption to maintain or strengthen ties to their ethnic group. Sport consumption can be utilized as a means of maintaining one's cultural identity (Stodolska \& Alexandris, 2004). Sport spectatorship can also provide opportunities to learn more about other cultures and build trust and understanding between diverse ethnic groups.

Numerous studies have examined the role of sport in the lives of immigrants (Harrolle \& Trail, 2007; Pons et al., 2001; Stodolska \& Alexandris, 2004). Both Harrolle and Trail and Pons et. al developed instruments for assessing the relationship between ethnic identity and sport fan behavior amongst immigrants. Stodolska and Alexandris conducted a qualitative study that examined the sport experiences and assimilation paths of Korean and Polish immigrants in Illinois. However, very few empirical studies have focused specifically on international students attending American universities and their sport consumption behavior. Kwon and Trail (2001) examined sport fan motives, team identity, and spectatorship frequency of international students. However, they only 
assessed their spectator behavior for football and basketball. Other studies that have

focused on international students in the sport context have either concentrated exclusively on one nationality group and their overall leisure behavior or strictly examined frequency of active participation (Li \& Stodolska, 2006; Yoh, Yang, \& Gordon, 2008). Therefore, there has been no holistic approach to understanding sport consumption behavior among international students. The data collected from the current study examines international students as a whole. Results will help the researchers gain a better understanding of the relationship among sport, socialization, and consumer behavior. Also, results from this study will enable American university athletic departments and sport marketers to better understand the unique characteristics of international students and their sport consumption behavior. Furthermore, this study will obtain important information that can be utilized to develop segmentation strategies more effectively. Sport programming and promotional efforts can be tailored to meet the needs of this growing market segment on college campuses.

\section{Review of Literature}

\section{Theoretical Foundation}

French sociologist, Emile Durkheim (1972) insisted that society is greater than the sum of its parts and coined the term collective consciousness. The collective consciousness, or shared attitudes and beliefs by a group of individuals, serves as a vehicle for maintaining social solidarity. Social solidarity is essential for society to function. With out this binding of individuals into a cohesive social unit, society would disintegrate; thus resulting in chaos (Durkheim). While typically we think of organized religion or educational systems as facilitators for group attachment, sport spectatorship 
facilitates this process as well. International students are able to experience feelings of belonging and solidarity through sport consumption alongside others that share their cultural background.

Identity theory, rooted in the work of George Herbert Mead, emphasizes conception of self and describes identity as internalized expectations resulting from roles that are entrenched in organized networks of social interaction (Allan). Individuals interact with one another in order to develop a set of behaviors that will reinforce identity (Mead, 1934). Mead takes into consideration both behavioral psychology and societal factors while attempting to explain the gestures and forms of communication displayed by the individual. Each individual determines his behavior in terms of what other individuals are doing. Gestures are meaningful symbols and indicate upcoming actions. The self arises from these social experiences and human beings initially develop their understanding of the world through "play" (Mead, 1934). "Play" refers to human development where roles are observed and then mimicked. As the individual progresses, he participates in the "game", which incorporates organized rules that require specific responses. During the "game" stage the individual must have the attitude of all the others involved in the activity. When this occurs, the individual's actions are determined by his assumptions of the others who are playing the game. Through this process the individual takes on the attitudes of the social group. Opinions, norms, and social response patterns are adopted, and individuals identify themselves with the group. Mead explains that this fusion of the individual with the group leads to an intense emotional experience. Through this fusion, feelings of solidarity and group belonging can emerge. Mead's concept is also useful for understanding the phenomenon of social solidarity and expands upon 
Durkheim's explanation of this idea. Through sport spectatorship, individuals are able to develop and maintain their identity.

According to symbolic interactionism, individuals organize their behavior in agreement with their expectations of others and depending upon their familiarity with the situation (Armstrong, 2007). Symbolic interaction can also be explained as a presentation of gestures and a response to the meanings of those gestures (Blumer). The meaning of things for an individual grows out of the ways in which other people act toward the individual with regard to the thing. Therefore, symbolic interactionism views meanings as social products. Social products are formed in and through the defining activities of individuals as they interact. The individual's actions are built up through their interpretation of the situations in which they are placed. Structural features, "such as culture, social systems, social stratification, or social roles, set conditions for the actions but do not determine the action" (Blumer, p. 88). Symbolic interactionism provides for individual agency and suggests that individuals do not actually act toward culture or social structure, but rather toward situations. Social organization "enters into action only to the extent to which it shapes situations and supplies fixed sets of symbols which people use when interpreting their situations" (Blumer, p. 88). Therefore, sport spectatorship is not simply an arena for expression of pre-existing factors; but rather a formative process. Sport spectatorship can symbolically define a group and can offer meaning that will guide and direct the future actions of the group's members.

Social exchange theory focuses on reciprocal relationships between individuals within social structures. The theory asserts that social exchanges are meaningful and build trust over time (Allan, 2007). Social exchanges are meaningful in that they imply or 
signify something beyond the mere action itself. According to Blau, social exchange is the starting device for social interaction and the formation of group structure. Before group identities, boundaries, roles, status positions, and norms are created; interaction is initiated out of a desire to gain something meaningful from the exchange (Allan). Social exchange theory can be applied to situations where international students consume sport alongside individuals that do not share their same cultural background. Spectatorship facilitates the exchange of norms and builds trust between the groups.

Milton Gordon's (1964) Assimilation in American Life offers a useful analysis of immigrant behavior and inter-group dynamics in the United States. Gordon examines and critiques the concepts and rhetoric of "total assimilation", "the melting pot", and "cultural pluralism" theories. Using these concepts as a starting point, he then builds his thesis by providing an in depth analysis of social structure and culture, subcultures, the nature of assimilation, theories of assimilation, the assessment of these theories, and finally; the implications. In his discussion on the nature of assimilation, Gordon provides a table that lists the forms or stages of assimilation and includes a corresponding sub-process or condition for each. He indicates that one of the most common forms is cultural assimilation by substitution where the individual substitutes their heritage and behavior pattern for another. Gordon explains that minority immigrants feel pressure to conform to the customs and behaviors of the dominant majority. According to the substitution model, minority immigrants may participate little or not at all in activities with their own ethnic group. Some immigrants make a conscious decision to adopt a cultural pluralism model. This enables them to participate in societies major institutions, such as sport, while still retaining their own ethnic heritage. 
Gordon critiques the Anglo-Conformity ideology and indicates that this form of assimilation results in "the disappearance of the ethnic group as a separate entity and the evaporation of its distinctive values" (Gordon, 1964, p. 81). He also appears to reject the "melting pot" concept and refers to it as rhetoric embedded into the American response to turn of the century immigration. While Theodore Roosevelt and Woodrow Wilson favored this ideology, Gordon views it as suggesting that immigrants are absorbed into mainstream American culture. Gordon (1964) challenges this notion and asserts that there are actually numerous "melting pots" or sub-societies, rather than a single American "melting pot". Gordon embraces the theory of "cultural pluralism", as he recognizes numerous societies within societies in the US. Immigrant groups often embrace the political and economic life as well as the English language in America. However; many immigrants still maintain ties to their ethnic group through religious worship, holidays, meals, music, games, and other behavior associated with their cultural heritage.

\section{Sport and Cultural Identity}

Burdsey (2008) provided a case study of the Amsterdam World Cup (WK Amsterdam), which is an amateur soccer competition and multicultural festival held annually. Framing the event within the context of the Dutch integration policy, Burdsey analyzed various conceptions of identity, community, and multiculturalism displayed by the participants and organizers of the event. WK Amsterdam is a men's soccer tournament which involves the city's diverse immigrant and refugee community. African, Middle Eastern, South Asian, and Caribbean countries are well represented, many of which were former Dutch colonies. However, the tournament organizers make a 
conscious attempt to ensure that the tournament is not dominated by Eurocentric expression.

WK Amsterdam is reveled as playing an important social role for all the represented communities, particularly for non-white minorities (Burdsey, 2008). The event facilitates valuable face-to-face interaction for communities. Athletes and spectators alike, express their cultural identity. However, much of Burdsey's focus is on the spectators. Many come to the event dressed in traditional costumes, participate in live musical performances and dances, offer different types of cuisine, and display flags from their homeland. Amsterdam's diverse ethnic minority populations display their desire for status and a sense of recognition within the community. However, Burdsey (2008) provides several examples that suggest the structure of the event and situations surrounding the event limit the effectiveness of the organizer's mission in facilitating solidarity. The sheer size of the venue allows, and possibly encourages, teams and spectators to spread out and keep separate. Also, by encouraging spectators to affiliate with a single team, the organizers limit the success of the project. Still, Burdsey is of the opinion that WK Amsterdam is more effective at embracing multi-cultural ideals and facilitating group cohesion than the majority of mainstream sporting events.

Glasgow Celtic was established in 1887 and is one of the more recognized soccer clubs in Europe. Historically the fan base for the team is derived from the immigrant Irish community in Glasgow. Celtic's great rival is Glasgow Rangers, and unfortunately; this bitter rivalry has been associated with sectarian problems. Matches between them are not simply a clash of two soccer powers, but a clash of cultures and ideologies (McMenemy $\&$ Poulter, 2005). Rangers are the traditional protestant team while Celtic is championed 
by the Scottish Catholics. McMenemy and Poulter administered a survey utilizing two email lists for Celtic fans in order to assess the affiliations, expressions of identity, and attitudes of Scots of Irish descent. The survey obtained demographic data and offered open ended questions. Of the 700 Celtic supporters e-mailed, 108 participated in the study.

It was not surprising that Glasgow Celtic was revealed by many to be a point of attachment for expressing their Irish identity and pride. However, the prevailing sentiment from the collection is one of a community that feels it is not encouraged to celebrate its Irishness by Scottish society, something it does through supporting the Celtic soccer team. Still, the majority of the participants indicated that they support the Scottish national soccer team and do not perceive any conflict in supporting Scotland and Celtic. A sizeable number of participants indicated that they remain loyal to Ireland in both national identity and national team support, despite many of them being third or fourth generation immigrants (McMenemy \& Poulter, 2005). For these individuals, their support of Celtic was not seen as being compatible with Scottishness. Regardless, the impact of Celtic on the identity of Scots with Irish heritage is important to examine. Support of Celtic provides an opportunity to express pride and solidarity in the Irish Catholic community.

Kösebalaban (2004) asserts that sport has been used by the media as a mechanism for drawing the boundaries of Turkish national identity. The researcher explains that "boundary marking is achieved through emphasizing and magnifying feelings of 'us' versus 'them' throughout the media's coverage" (Kösebalaban, p. 47). The prevailing theme in the headlines of both the Islamic and the secular media is a characterization of 
Europe as the 'other' of Turkish national identity. The media frames these sport encounters with high levels of patriotism and national fervor "while reinforcing the mental imaginations of belonging to a supranational cultural identity" (p. 47). Sport (i.e., soccer) provided Turkey with a politically neutral point of attachment for their diverse society to re-define their boundaries of national identity (Kösebalaban). Capitalizing on Turkey's success in the 2002 World Cup, the media seized this opportunity to transmit messages regarding cultural identity.

International Students, Ethnicity, and Sport Consumer Behavior

While virtually all athletic departments recognize American college students as a specific target market, it is not evident that international students are being accessed as a market segment (Kwon \& Trail, 2001). To date, Kwon and Trail's study provides the most comprehensive analysis of international student's sport consumer behavior currently available. The purpose of their study was to determine if international students should be considered a segmented target market. Kwon and Trail analyzed the differences between American and international students' attendance at college football and basketball games, frequency of television spectatorship for college football and basketball, levels of identification with the football and basketball team affiliated with the university attended, and psychological motives for sport consumption.

Results indicated that international students attended significantly fewer football and basketball games than American students. However, despite their attendance being lower; there was not a statistically significant difference in the number of games watched on television between international students and American students. Kwon and Trail (2001) indicate that for international students, the interest level is apparent but it is not 
being expressed by attendance. Additionally, the international students' identification level with the football and basketball team was relatively high and approximately equal to the American students' identification level. Kwon and Trail suggest that these results may indicate there is an underdeveloped market that could be easily accessed. When comparing the motives between international students and American students, drama was the primary motive for consumption for both international students and American students. The only motive that was considerably different between the two groups was aesthetics. The aesthetic motive was higher for international students than for American students.

Based on these findings, it appears that targeting international students as a specific market segment might result in increased attendance at football and basketball games. Unfortunately, Kwon and Trail (2001) neglected to assess consumer behavior information from international students for sports outside of football and basketball. While football and men's basketball are traditionally seen as the revenue generating sports for a college athletic department, these may not be the sports that international students have the highest interest in. Also, cultural variables were not examined by Kwon and Trail. Assessing cultural identity and ethnic variables should provide researchers with a richer understanding of the unique consumer characteristics of international students.

Armstrong (2002) critiques previous sport fan motivation studies and stresses that these investigations have neglected to include racial and ethnic variables. Armstrong also indicates that previous sport fan motivation studies utilized a predominately Caucasian sample for data collection. As such, the purpose of Armstrong's study was to examine sport fan motives of consumers attending a Historically Black Colleges and Universities 
(HBCU) all-star basketball event in order to determine if consumer motives differed between African Americans and the findings of previous studies. Another purpose of Armstrong's investigation was to intróduce a cultural affiliation motive which had previously been ignored by researchers. Results from the study revealed that the exploratory cultural affiliation motive should be considered as an important motive for sport consumption among African American consumers. The cultural affiliation motive ranked fifth, which was exactly in the middle, as four factors were more influential and four factors were less influential. Furthermore, the items comprising the cultural affiliation motive had the second highest internal consistency rating among the nine motives included in the model. Results from the study suggested the Black consumers' responses to several of the motives differed from those previously reported as yielded by majority Caucasian samples (Armstrong, 2002). Additionally, gender differences were less pronounced in the HBCU sample when compared to previous sport fan motivation studies. While Armstrong's study only examined sport consumer motives and did not target international students, it still provides useful information for the current study. The cultural affiliation motive included in the model aided in the explanation of sport consumer behavior. Moreover, the results suggest that the ethnicity of the sample impacted sport consumer behavior; supporting the use of ethnic and cultural segmentation strategies.

Harrolle and Trail (2007) did not examine international students; however their assessment of sports identification, ethnic identification, and acculturation among Latinos in the United States is useful for the current study. Similar to the current study, Mead's identity theory (1934) was incorporated into their theoretical frame. The Latino 
community in the US is the largest minority segment as well as the fastest-growing segment of the US population (Harrolle \& Trail, 2007). The majority of Latinos that participated in Harrolle and Trail's study were highly acculturated with the dominant US society. Results indicated that as the ethnic identity of Latinos increased, their identification with hockey decreased. This displays the relationship between ethnic identity and sport fan identification. Acculturation had a small influence on Latino's identification with American football, baseball, basketball and sport in general. However, even when levels of ethnic identity and acculturation varied, attachment to soccer remained the same. The researchers also indicated that for Latinos as a whole, ethnic identity and acculturation had a greater impact on their identification with American football than for all the other sports examined. These findings offer sport marketers involved in soccer and American football useful information about the Latino consumer segment. McCarthy (1998) also identifies Latinos as overlooked sport consumers. Latino consumers exist in a unique bilingual and bicultural market allowing them to take part in mainstream American activities, such as sport spectatorship, without having to forfeit their Latin culture (McCarthy).

Based on the review of literature and pursuant to the exploratory nature of this study, the researchers seek to develop a better understanding of international students' sport consumption behavior by advancing the following research questions:

Research Question 1: Will the international students' nationality impact their sport spectatorship selection?

Research Question 2: Will the international students' nationality impact their sport media consumption? 
Research Question 3: Will the international students' gender, age, or interaction of gender and age, impact their sport media consumption?

Research Question 4: Will the length of time that the international students have been living in the United States significantly impact their sport media consumption?

Research Question 5: Will the international students' nationality impact their sport spectatorship behavior with regards to attending sporting events with individuals of the same cultural background or with individuals of a different cultural background?

Research Question 6: Will the international students' gender impact their sport spectatorship behavior with regards to attending sporting events with individuals of the same cultural background or with individuals of a different cultural background?

Methods

\section{Participants}

The participants within this study included international students attending one university located in the Mid-West, one located in the West, and two universities located in the South that voluntarily responded to an online survey distributed to them via their universities' international studies department. Written permission from the university's international studies office and Institutional Review Board (IRB) approval was obtained. These four universities are similar in that they are large comprehensive universities with undergraduate, masters, and doctoral students, thus providing a representative sample of students from a variety of degree programs. The universities in this study are located in different geographic regions in the United States. This also assists the researchers in obtaining a more representative sample. Moreover, these universities were selected for participation in the study because they were very enthusiastic about the research topic 
and indicated that the data obtained would provide useful information for their international studies office as well as their athletic department.

Consequently, a total of 242 responses were collected. Of those, 240 surveys were found to be useable, with two being discarded due to having too many missing values. Of the 240 participants, approximately, 36\% were from Asian nations (eg. China, Japan, Korea), 25\% were from South Asian nations (eg. India, Pakistan, Bangladesh), 11\% were from European nations (eg. Germany, France, Spain), 10\% were from either the United Kingdom, Australia, or Canada, 9\% were from Latin American nations (eg. Brazil, Mexico, Dominican Republic), 5\% were from Middle Eastern nations (eg. Syria, Saudi Arabia, Egypt), and 4\% were from African nations (eg. Nigeria, Kenya, Cameroon). Approximately, $30 \%$ of the international students had been living in the United States for 1 year or less, 23\% had been living in the US for more than 1 year and less than 2, $18 \%$ had been living in the US between 2 and 3 years, and 29\% had been living in the US for more than 3 years. There were 133 males (55.4\%) and 107 females (44.6\%) that completed the survey.

\section{Instrument}

The instrument that was utilized in this study was developed by the researchers through a review of relevant literature, recommendations from an expert panel, results from a focus group, content validity testing, and modification of the preliminary scale. The survey consisted of three sections: (a) Sport and Cultural Identity Scale (SCIS) (Allen, Drane, \& Byon, 2009), (b) sport spectatorship and media consumption, and (c) demographics. The SCIS was developed by the researchers and measured the international students' maintenance of cultural identity and assimilation through active 
participation in sport. The SCIS consisted of twenty items under two factors; cultural maintenance and cultural assimilation through sport. Through exploratory factor analysis and reliability testing, these factors were found to be valid and reliable measures of sport participation behavior among international students in the United States. For the purposes of the current study, the researchers primarily focused on spectatorship and media consumption, rather than active sport participation.

In order to obtain a description of the sample, various demographic variables were included in the questionnaire, which consisted of age, nationality, gender, and length of time spent living in the United States. Sport selection for spectatorship instructed the respondent to rank their top three sports based on frequency of consumption. There were eighteen different sports to select from and there was the option of 'other' for respondents that frequently attended or watched a non-listed sport. Respondents were also instructed to determine if they most frequently attended live sporting events with individuals of the same cultural background or with individuals of a different cultural background. Lastly, students were asked to determine if they most frequently consumed domestic sport media, foreign sport media, or domestic and foreign sport media equally.

\section{Procedures}

The researchers submitted the initial instrument to a panel of eight experts in the field of sport management, sport sociology, recreation, and measurement. The panel of experts evaluated the face and content validity of the entire instrument. Feedback from the panel of experts was utilized to make initial adjustments. Next, the researchers conducted a focus group with four English Learning Institute students from one of the universities participating in the study. Based on the feedback from the focus group, the 
initial questionnaire was modified again in order to make the wording easily understood by students having English as their second language. The expert panel reviewed the instrument again and it was supported. As previously stated, international students participated in this study by responding to an e-mail message which contained a link to the online version of the survey. International students that had an e-mail address registered with their international studies office received a message notifying them of the research study. Respondents completed the survey online and the data were transferred directly to a file that only the researchers had access to. As a result, a total of 2935 international students were e-mailed a link to the survey and a total of 242 returned a survey. This represents a return rate of $8.2 \%$. It is important to note that not all international students consider themselves sport consumers. Therefore, the instrument is only relevant to a portion of the students e-mailed; making an accurate response rate impossible to calculate.

\section{Data Analyses}

Descriptive statistics were calculated for the socio-demographic variables using SPSS version 16.0 (SPSS, 2007). Percentages were calculated for the spectatorship and media consumption variables (Table 3 ). In order to determine if there was a statistically significant relationship between nationality and sport selection, a chi-square test was conducted. An ANOVA test was utilized to determine if international students' nationality impacted their sport media consumption. A two-way ANOVA was performed in order to examine the relationship between, gender, age, and the interaction of gender and age, with sport media consumption. In order to determine if the length of time the international student has spent living in the United States impacted their sport media 
consumption, an ANOVA test was conducted. A chi-square test was performed in order to examine the relationship between nationality and sport spectatorship behavior with regards to attending sporting events with individuals of the same cultural background or with individuals of a different cultural background. Lastly, an ANOVA test was performed in order to determine if the international students' gender impacted their sport spectatorship behavior with regards to attending sporting events with individuals of the same cultural background or with individuals of a different cultural background.

Results

Before the researchers could analyze the results of the chi-square test, a series of assumption tests were performed. The assumption tests included: a) having two categorical variables, b) independence of observation, and c) at least five samples in all cells. There were no violations of these assumptions. Results of the chi-square test indicated there was a statistically significant relationship between the international students' nationality and the specific sports that they most frequently consumed as spectators $\left(x^{2}=208.41, p<.01\right)$. Inspection of the cross tabulation table allowed the researchers to determine the sport spectatorship preferences of each nationality group (Table 4). International students from Asian nations most frequently consumed basketball, while South Asians most frequently consumed cricket. International students from Latin American and European nations attended or watched soccer games more than any other sport. For international students from African nations, there was an equal split between soccer and basketball, as these two sports were most frequently consumed. The international students from the United Kingdom, Canada, and Australia were also split between two sports that they most frequently consumed, however; their sport preference 
was for basketball and American football. Students from Middle-Eastern nations were more diversified in their sport spectatorship. While soccer was the most frequently consumed sport for this group, this was followed closely by basketball and swimming.

Before examining the results of the first ANOVA test, the researchers conducted a series of assumption tests to see if the data were appropriate for ANOVA testing. The assumption tests included: (a) independence of observations, (b) homoscedasticity, and (c) normality. Hair et al. (2005) argued that the independence of the data could be ensured by random sampling. The researchers obtained independent observations by emailing a link to the survey to all of the international students attending the universities participating in the study. The second assumption test was conducted using Levene's test for the dependent variable; media consumption. As a result, the dependent variable showed a non-significant value $(p>.05)$; indicating equal variances were placed for the dependent variable. The assumption of normality for the dependent variable was examined by means of skewness and kurtosis values. According to Chou and Bentler (1995), absolute value less than 3.0 for skewness and kurtosis would be acceptable. Based on this criterion, all of the values were within acceptable threshold (i.e., -.32 for skewness and -1.5 for kurtosis). Based on a series of assumption tests related to ANOVA, it was determined that the current data met all the assumption tests. Results of the ANOVA test indicated that nationality did not have a statistically significant impact on sport media consumption $F(6,201)=1.53,(p>.05)$.

A two-way ANOVA was conducted utilizing the same assumption tests as the previous ANOVA test. All of the assumptions were met and the researchers proceeded with the analysis. As a result of the two-way ANOVA, the researchers identified that 
there was not a significant main effect between gender and sport media consumption $F$ $(1,199)=.66,(p>.05)$. Also, the interaction between gender and age did not significantly impact sport media consumption $F(3,199)=1.62,(p>.05)$. However, there was a statistically significant main effect between age and sport media consumption $F(3,199)=3.12,(p<.05)$. Results of a Tukey post-hoc test revealed that international students over 30 years old consumed domestic sport media significantly more than international students aged 21-24. There was not a significant difference between these two age groups and international students aged 18-20 or 25-30.

Another ANOVA test was performed in order to examine the relationship between the length of time the international student has lived in the United States and their sport media consumption. Again, the same series of assumptions tests were performed and there were no violations. Levene's test for the dependent variable showed a nonsignificant value $(p>.05)$; indicating equal variances were placed for the dependent variable. The assumptions of independence of observation and normality were also met. Results of the ANOVA test revealed that the length of time the international students has lived in the US statistically significantly impacted their sport media consumption $F$ ( 3 , $204)=2.72,(p<.05)$. A Tukey post-hoc test indicated that international students that have been living in the US for more than three years consumed significantly more domestic media than international students that have lived US for one year or less.

Results of a chi-square test indicated that there was not a statistically significant relationship between nationality and sport spectatorship behavior with regards to attending sporting events with individuals of the same cultural background or with individuals of a different cultural background $\left(x^{2}=8.52, p>.05\right)$. An ANOVA test was 
then performed in order to determine if the international students' gender impacted their sport spectatorship behavior with regards to attending sporting events with individuals of the same cultural background or with individuals of a different cultural background. Results of the ANOVA test revealed that the international students' gender statistically significantly impacted their sport spectatorship behavior with regards to attending sporting events with individuals of the same cultural background or with individuals of a different cultural background $F(1,201)=5.43,(p<.05)$. Inspection of the means indicated that males were more likely to attend live sporting events with individuals from the same cultural background than females.

The data collection was also used to examine active sport participation behavior among international students with regard to socialization, cultural maintenance, and cultural assimilation. An exploratory factor analysis resulted in a two factor solution. These two factors, cultural maintenance and cultural assimilation; were both internally consistent. Due to the exploratory nature of the current study, the researchers were interested in examining the relationship between these two factors and the spectatorship behavior variable regarding attending sporting events with individuals of the same cultural background or with individuals of a different cultural background. While the cultural maintenance and cultural assimilation through sport factors pertained to active participation, the researchers consider both active participation and sport spectatorship to be forms of sport consumption. Two Pearson correlations tests were conducted in order to examine this relationship. A series of assumption tests were conducted before the results of the Pearson correlation tests could be examined. The assumption tests included: a) mean of $\mathrm{Y}$ is related to $\mathrm{X}$ by the linear equation, $\mathrm{b}$ ) the conditional standard deviation is 
identical at each X-value, c) independence of observations; and d) normality. There were no violations to these assumptions and the researchers proceeded with the analysis. Results of the first Pearson correlation test indicated that the cultural maintenance variable was not significantly related to the spectatorship behavior variable $(p>.05)$. However, results of the second Pearson correlation test revealed that there was a statistically significant relationship between the cultural assimilation variable and the sport spectatorship behavior variable $(p<.05)$. Inspection of the means revealed that international students that attended live sporting events with individuals from a different cultural background scored higher on the cultural assimilation through sport participation variable than international students that attended live sporting events with individuals of the same cultural background.

\section{Discussion}

The researchers are only aware of one previous empirical examination of sport spectatorship behavior pertaining specifically to international students (Kwon \& Trail, 2001). However, this previous study only examined sport fan motives, team identification, and frequency of spectatorship for football and basketball. Also, Kwon and Trail's study did not attempt to examine any variables pertaining to socialization or cultural identity. The researchers in the current seek to address these gaps in the body of research by examining international students' sport selection for spectatorship, media consumption, and sport spectatorship behavior with regards to attending sporting events with individuals of the same cultural background or with individuals of a different cultural background. Previous studies have suggested that sport spectatorship behavior is related to maintenance of cultural identity and cultural assimilation (Burdsey, 2008; 
Kösebalaban, 2004). Researchers of the current study assert that sport spectatorship at live events with individuals of the same cultural background provides opportunities for maintenance of cultural identity and spectatorship with individuals of a different cultural background provides opportunities for assimilation. Also, sport media consumption can serve as vehicle for maintenance of cultural identity and assimilation.

Results from the current study showed there was a statistically significant relationship between the international students' nationality and the specific sports that they most frequently consumed as spectators. This provides sport marketers and professionals with extremely useful information as they are able to develop segmentation strategies based on nationality and expressed interest in particular sports. The international students from Asian nations participating in the study most frequently consumed basketball while South Asians most frequently consumed cricket. Considering that these are typically the two largest international student segments, this information is crucial for sport managers and marketers. While basketball is a mainstream spectator sport in the United States, cricket is not. Depending on the number of South Asian students attending a university, recreational sport departments may want to consider programming an annual cricket event. Also, cable media outlets servicing areas with large numbers of South Asians may want to consider televising major cricket matches during non-prime-time slots.

It did not come as a surprise that international students from Latin American and European nations consumed soccer more than any other sport. However, unless there are large numbers of Latin American and European international students on campus, this information may not prove fruitful for sport managers and marketers. For international 
students from African nations, there was an equal split between soccer and basketball for the most frequently consumed sport. African international students made up the smallest segment of the current study, therefore the practical implications of their sport preference may be limited. International students from the United Kingdom, Canada, and Australia were also split between two sports that they most frequently consumed. These sports were basketball and American football. In fact, this group of international students was the only group that expressed a recognizable preference for American football. International students from Middle-Eastern nations most frequently consumed soccer, however; this was followed closely by basketball and swimming. Again, unless there are large numbers of Middle-Eastern students on campus; these findings may not offer practical implications. The researcher did not detect a significant relationship between nationality and sport media consumption.

Results from the current study showed that age significantly impacted sport media consumption. More specifically, international students over 30 years old consumed domestic sport media significantly more than international students aged 21-24. Domestic sport media outlets that are interested in attracting international students toward their product are recommended to target international students 30 years or older. Typically, students of this age group would be engaged in graduate level education; possibly seeking a doctorate. Based on the findings from the current study, it does not appear to be beneficial for domestic sport media outlets to target international students aged 21-24. Also, results from the current study revealed that international students that have been living in the United States for more than three years consumed significantly more domestic media than international students that have lived US for one year or less. These 
results may be describing the same relationship found between international students 30 years or older and international students aged 21-24. It appears that international students that have been in the US longer and are relatively older than other international students consume the most domestic sport media. It is the researchers' assertion that consumption of domestic sport media offers international students opportunities for assimilation while consumption of foreign sport media offers unique opportunities of cultural maintenance. Kösebalaban (2004) explains that boundary marking is achieved by the sport media through emphasizing and magnifying feelings of 'us' versus 'them'. International students that are primarily consuming domestic media may be developing a new American identity and internalizing feelings of belonging. Conversely, international students that are frequently consuming sport media from their homeland can utilize this behavior for maintaining their identity associated with their culture.

Interestingly, the researchers in the current study revealed that gender significantly impacted sport spectatorship behavior with regards to attending sporting events with individuals of the same cultural background or with individuals of a different cultural background. More specifically, males were more likely to attend live sporting events with individuals from the same cultural background than females. Attending live sporting events with individuals of the same cultural background provides the international student with opportunities for cultural maintenance. It is quite possible that males are displaying a greater desire for cultural maintenance through sport spectatorship than females. The researcher did not detect a significant relationship between nationality and sport spectatorship behavior with regards to attending sporting events with individuals of the same cultural background or with individuals of a different cultural background. 
There was a statistically significant relationship between the cultural assimilation variable measured by the instrument and the sport spectatorship behavior variable regarding attendance at sporting events with individuals of the same cultural background or with individuals of a different cultural background. Through further inspection, the researcher revealed that international students attending live sporting events with individuals from a different cultural background scored higher on the cultural assimilation through active sport participation variable than international students attending live sports with individuals of the same cultural background. While the assimilation through sport variable was relative to recreational sport participation, it makes logical sense that these two variables would be related. Both active participation and sport spectatorship offer opportunities for international students to assimilate into their new cultural environment. Attending live sporting events with individuals from a different cultural background can provide beneficial socialization opportunities that may open doors for cultural assimilation.

\section{Marketing Implications}

The current study provides sport marketers with crucial information for marketing their product to international students. Kwon and Trail (2001) indicate that international students may be an underserved market segment. Results from Kwon and Trail's study indicated that international students attended fewer basketball and football games than American students, however; their television spectatorship of basketball and football was not statistically different from that of American students. Therefore, international students are expressing an interest in these particular sports. However, Kwon and Trail only assessed consumer behavior for football and basketball. Results of the current study 
indicate that the only international student segment expressing a recognizable interest in consuming American football were students from the United Kingdom, Canada, and Australia. It is critical that sport marketers take note that these were the only international students that frequently consumed American football. Football is typically viewed as a revenue generating sport on college campuses and significant marketing resources are allocated to promote the football product. When there are significant numbers of students from the United Kingdom, Canada, and Australia on campus; utilizing marketing resources to target these students may result in increased attendance. In the current study, $10 \%$ of the participants were from these nations.

The marketing implications for basketball are much greater. International students from Asian nations most frequently consumed basketball. Asians made up the largest group in the current study and this is typical for college campuses in the United States. Marketing the basketball product on college campuses to international students from Asian nations may be a worthwhile strategy as this may be an untapped market segment. In fact, marketing basketball to international students as a whole should prove fruitful. International students from Middle-Eastern and African nations, the United Kingdom, Canada, and Australia, displayed frequent spectatorship of basketball. Also, it is important to realize that there may be a link between basketball spectatorship and cultural identity. Currently, there are professional basketball players competing in the National Basketball Association (NBA) from China, England, Canada, Australia, and numerous Latin American and European nations. One possible result of the continuous globalization of basketball is enhanced cultural attachment with the sport. Some international students may utilize basketball spectatorship as a means of cultural 
expression. Sport marketers are able to emphasize the global appeal and cultural aspects of the sport to consumers.

The sport of soccer is not always programmed by college athletic departments. In fact, even when it is offered as a varsity sport by the university, it may strictly be a women's soccer team. Additionally, the sport of soccer is not traditionally viewed as a revenue generating sport. However, in situations where a university campus has large numbers of international students from Latin American and European nations; soccer may be deserving of programming and marketing consideration. Also, international students form African and Middle-Eastern nations displayed high spectatorship levels of soccer. Sport marketers should also recognize the relationship between soccer and cultural identity. For some international students, soccer spectatorship is a vehicle for cultural expression. Soccer is the world's most popular spectator sport. If a university athletic department is located in area where there are loyal soccer fans and there are also large numbers of international students from Latin American, European, African, and Middle-Eastern nations; resources spent on programming and marketing soccer may be worth considering. Even if soccer can never become a revenue generating sport for the university, tapping into local soccer fans and the international student segment may help reduce the amount of money lost by the university from programming intercollegiate soccer.

\section{Limitations and Future Research}

The current study was limited by utilizing only four universities during one semester of enrollment for obtaining data from international students. It is crucial that the researchers conduct a follow up study in order to further validate the findings from the 
current study regarding sport consumption behavior among international students attending American universities. The researchers plan to target different universities for participation in a follow up study. This will allow for the researchers to more accurately generalize the findings. In the current study, there were no universities from the Northeastern United States or from the West Coast. Universities from these regions of the US should be contacted in an attempt to gain a more representative sample. It is quite possible that the international students located in these regions could display different consumer behavior characteristics than those found in the current study.

Also, the researchers neglected to include factors measuring cultural maintenance and cultural assimilation through sport spectatorship. The instrument utilized for this study measured cultural maintenance and cultural assimilation through active sport participation. For the follow up study, the researchers will include a scale for assessing cultural maintenance and cultural assimilation through sport spectatorship and will conduct another exploratory factor analysis as there will be new constructs included in the model. This will allow the researchers to obtain a deeper understanding of the international student sport consumer segment.

\section{Conclusion}

International students attending American universities are an untapped resource for sport marketers. Results from the current study indicated there was a significant relationship between nationality and the sports international students consumed as spectators. Age and length of time spent living in the United States significantly impacted sport media consumption patterns. Also, the international students' gender significantly impacted their sport spectatorship with regards to attending live events with individuals 
of the same cultural background or with individuals of a different cultural background. Sport marketers can use information from this study to target this growing segment. 


\section{References}

Allen, J. T., Drane, D. D., \& Byon, K. K. (2009, May). Conceptualization of the international students sport participation and consumption scale. Paper presented at the Annual Conference of the North American Society for Sport Management, Columbia, SC.

Allan, K. (2007). The social lens: An invitation to social and sociological theory. Thousand Oaks, CA: Sage.

Armstrong, K. L. (2002). Race and sport consumption motivations: A preliminary investigation of a black consumers' sport motivation scale. Journal of Sport Behavior, 25(4), 309-330.

Armstrong, K. L. (2007). Self, situations, and sport consumption: An exploratory study of symbolic interactionism. Journal of Sport Behavior, 30, 111-129.

Blumer, H. (1969). Symbolic interactionism: Perspective and method. Englewood Cliffs, NJ: Prentice Hall.

Burdsey, D. (2008). Contested conceptions of identity, community and multiculturalism in the staging of alternative sport events: A case study of the Amsterdam World Cup football tournament. Leisure Studies, 27, 259-277.

Chou, C. P., \& Bentler, P. M. (1995). Estimates and tests in structural equation modeling. In R. H. Hoyle (Ed.), Structural equation modeling: Concepts, issues and applications (pp. 37-55). Thousand Oaks, CA: Sage.

Durkheim, E. (1972). Restitutive sanctions and the relationship between mechanical and organic solidarity. In A. Giddens (Ed.), Selected writings, (pp. 135-140). London: Cambridge University Press. (Original work published 1960) 
Gordon, M. M. (1964). Assimilation in American life: the role of race, religions and national origins. New York: Oxford University Press.

Hair, J. F., Black, W. C., Babin, B. J., Anderson, R. E., \& Tatham, R. L. (2005). Multivariate data analysis (6th ed.). Upper Saddle River, NJ: Prentice Hall.

Harrolle, M. G., \& Trail, G. T. (2007). Ethnic identification, acculturation and sports identification of Latinos in the United States. International Journal of Sports Marketing \& Sponsorship, 8(3), 234-253.

Institute of International Education, Open Doors (2008). International students on U.S. campuses at all-time high. Retrieved May 9, 2009, from http://www.iie.org/

Kösebalaban, H. (2004). Turkish media and sport coverage: marking boundaries of national identity. Critique: Critical Middle Eastern Studies, 13, 47-64.

Kwon, H., \& Trail, G. T. (2001). Sport fan motivation: A comparison of American students and international students. Sport Marketing Quarterly, 10(3), 147-155.

Li, M., \& Stodolska, M. (2006). Transnationalism, leisure, and Chinese graduate students in the United States. Leisure Sciences, 28(1), 39-55.

McCarthy, L. M. (1998). Marketing to Hispanic consumers. Sport Marketing Quarterly, $7(4), 19-24$

McMenemy, D., \& Poulter, A. (2005). An identity of two halves? Irish Studies Review, 13, $139-150$.

Mead, G. H. (1934). Mind, self, \& society. Chicago: University of Chicago Press. 
Pons, F., Laroche, M., Nyeck, S., \& Perreault, S. (2001). Role of sporting events as ethnoculture's emblems: Impact of acculturation and ethnic identity on consumers' orientation toward sporting events. Sport Marketing Quarterly, 10(4), 231-240.

Stodolska, M., \& Alexandris, K. (2004). The role of recreational sport in the adaptation of first generation immigrants in the United States. Journal of Leisure Research, 36(3), 379-413.

Yoh, T., Yang, H., \& Gordon, B. (2008). Status of participation in physical activities among international students attending colleges and universities in the United States. College Student Journal, 42(4), 1110-1117. 


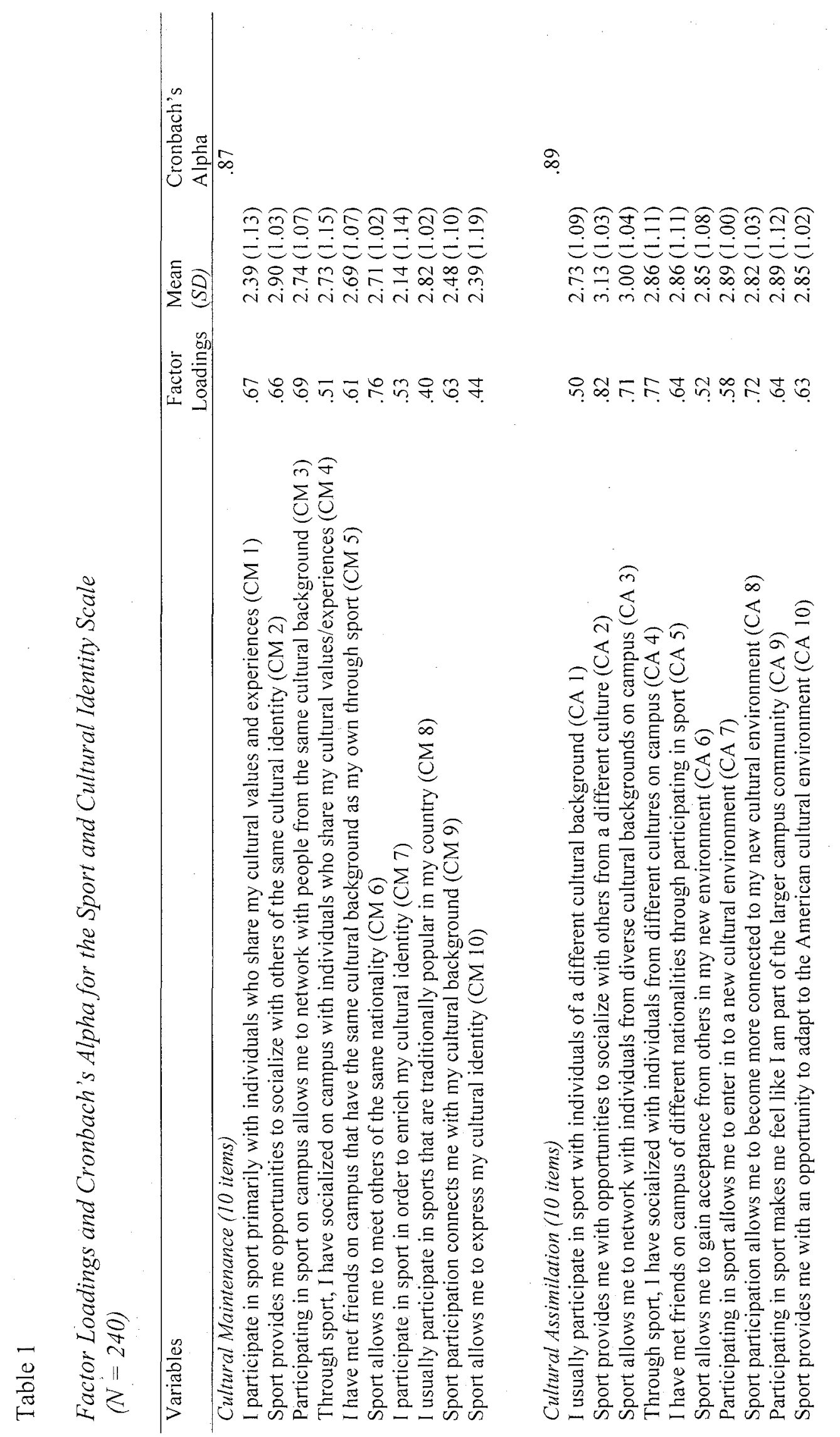

I 
Table 2

Top three sports for participation based on nationality

\begin{tabular}{|c|c|c|c|}
\hline Nationality Group & $I^{s t}$ & $2^{\text {nd }}$ & $3^{\text {rd }}$ \\
\hline Asia & Badminton & Basketball & Swimming \\
\hline South Asia & Cricket & Badminton & Racquetball/Squash \\
\hline Europe & Soccer- & Running/Track \& Field & Racquetball/Squash \\
\hline Canada/UK/Australia & Running/Track \&Field & Basketball & Baseball/Softball \\
\hline Latin America & Soccer & Running/Track \&Field & Volleyball \\
\hline Middle East & Swimming & Tennis & Soccer \\
\hline Africa & Soccer & Rugby & Racquetball/Squash \\
\hline
\end{tabular}

Note. International students from Canada/UK/Australia: basketball and baseball/softball tied for $2^{\text {nd }}$. 


\section{Table 3}

Percentages for sport spectatorship behaviors $(N=240)$

\begin{tabular}{lc}
\hline Spectator Behavior & Percentage \\
\hline $\begin{array}{l}\text { Attend events with individuals of } \\
\text { the same cultural background }\end{array}$ & $61 \%$ \\
$\begin{array}{l}\text { Attend events with individuals } \\
\text { of a different cultural background }\end{array}$ & $39 \%$ \\
$\begin{array}{l}\text { Consume domestic sport media } \\
\text { most frequently }\end{array}$ & $29 \%$ \\
$\begin{array}{l}\text { Consume international sport } \\
\text { media most frequently }\end{array}$ & $25 \%$ \\
$\begin{array}{l}\text { Consume domestic and international } \\
\text { sport media equally }\end{array}$ & $46 \%$, \\
\end{tabular}




\section{Table 4}

Top three sports for spectatorship based on nationality $(N=240)$

\begin{tabular}{llll}
\hline Nationality Group & $1^{\text {st }}$ & $2^{\text {nd }}$ & $3 r d$ \\
\hline Asia & Basketball & Soccer & Tennis \\
South Asia & Cricket & Tennis & Basketball \\
Europe & Soccer & American Football & Tennis \\
Canada/UK/Australia & Basketball & American Football & Ice Hockey \\
Latin America & Soccer & Basketball & Volleyball \\
Middle East & Soccer & Basketball & Swimming \\
Africa & Soccer & Basketball & None
\end{tabular}

Note. International students from African nations: soccer and basketball tied for 1st.

International students from the UK, Canada, and Australia: basketball and American football tied for $1^{\text {st }}$. 


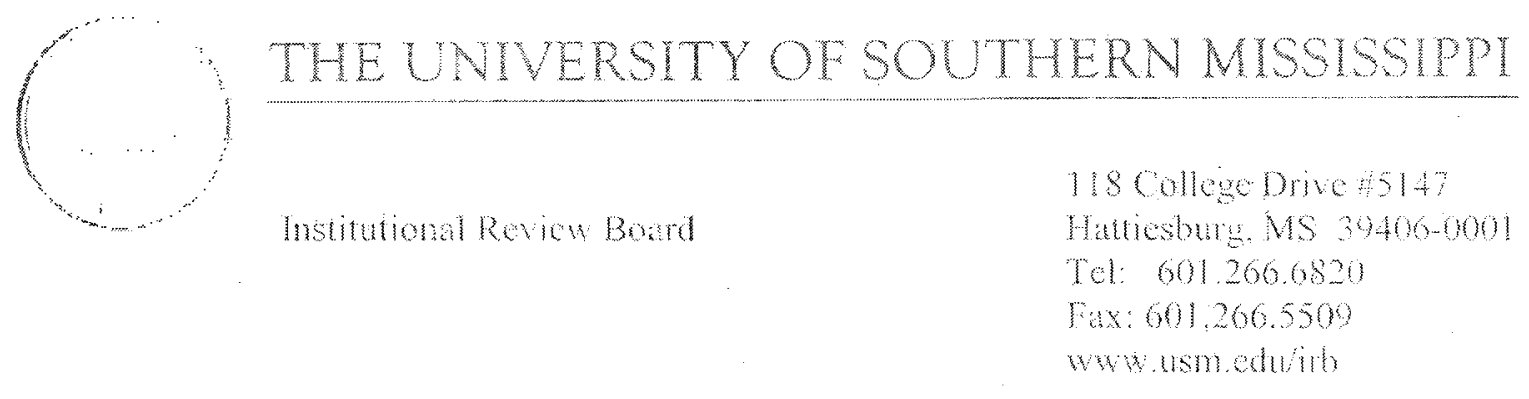

\section{HUMAN SUBJECTS PROTECTION REVIEW COMMITTEE NOTICE OF COMMITTEE ACTION}

The project has been reviewed by The University of Southem Mississippi Human Subjects Protection Review Committee in accordance with Federal Drug Administration regulations (21 CFR 26, 111), Department of Health and Human Services (45 CFR Pant 46), and university guidelines to ensure adherence to the following criteria:

- The risks to subjects are minimized.

- The risks to subjects are reasonable in relation to the anticipated benefits.

- The selection of subjects is equitable.

- Informed consent is adequate and appropriately documented.

- Where appropriate, the research plan makes adequate provisions for monitoring the data collected to ensure the safety of the subjects

- Where appropriate, there are adequate provisions to protect the privacy of subjects and to maintain the confidentiality of all data.

- Appropriate additional safeguards have been included to protect vuinerable subjects.

- Any unanticipated, serious, or continuing problems encountered regarding risks to subjects must be reported immediately, but not later than 10 days following the event. This should be reported to the IRB Office via the "Adverse Effect Report Form",

- If approved, the maximum period of approval is limited to twelve months.

Projects that exceed this period must submit an application for renewal or continuation.

PROTOCOL NUMBER: 29033002

PROJECT TITLE: Sport as a Vehicle for Socialization, Maintenance of Cultural Identity, and Assimilation: International Students Attending American Universities PROPOSED PROJECT DATES: 03/23/09 to 06/15/09.

PROJECT TYPE: Dissertation or Thesis

PRINCIPAL INVESTIGATORS: James Allen

COLLEGEIDIVISION: College of Health

DEPARTMENT: Human Performance \& Recreation

FUNDING AGENCY: N/A

HSPRC COMMITTEE ACTION: Exempt Approval

PERIOD OF APPROVAL: 04/13/09 to 04/12/10

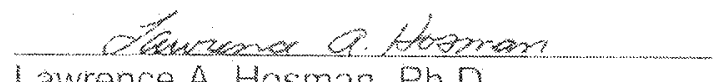

Hawrence A. Hosman, Ph.D

HSPRC Chair

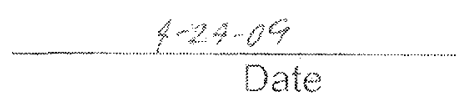




\section{INTERNATIONAL STUDENTS SPORT PARTICIPATION AND CONSUMPTION SURVEY}

Instructions: Please evaluate how true or untrue you feel the following statements are about your recreational sport participation. For the purposes of this study, RECREATIONAL SPORT is defined as organized or casual competitive sports and excludes NCAA or professional sport participation. This study will provide information that can be used by sport programming and marketing departments on college campuses.

1. I participate in recreational sport primarily with individuals who share my cultural values and experiences

\begin{tabular}{|c|c|}
\hline $\begin{array}{l}\text { Totally } \\
\text { Untrue }\end{array}$ & $\begin{array}{l}\text { Somewhat } \\
\text { Untrue }\end{array}$ \\
\hline
\end{tabular}

2. I participate in recreational sport in order to enrich my cultural identity

$\begin{array}{lccc}\text { Totally } & \text { Somewhat } & \text { Somewhat } & \text { Totally True Unsure } \\ \text { Untrue } & \text { Untrue } & \text { True } & \end{array}$

3. I usually participate in recreational sport with individuals of a different cultural background

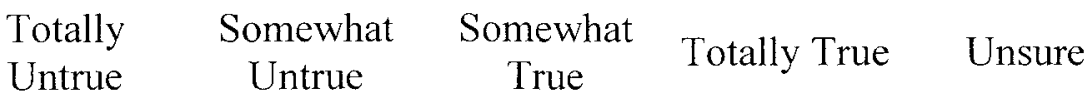

4. I participate in recreational sports because it helps me learn more about popular culture in the United States

$\begin{array}{lcccc}\text { Totally } & \text { Somewhat } & \text { Somewhat } & \text { Totally True } & \text { Unsure } \\ \text { Untrue } & \text { Untrue } & \text { True } & \text { The }\end{array}$

5. I usually participate in recreational sports that are traditionally popular in my country

$\begin{array}{lccc}\text { Totally } & \text { Somewhat } & \text { Somewhat } \\ \text { Untrue } & \text { Untrue } & \text { True } & \text { Totally True Unsure }\end{array}$

6. Recreational sport provides me with opportunities to socialize with others from a different culture

$\begin{array}{lcccc}\text { Totally } & \text { Somewhat } & \text { Somewhat } \\ \text { Untrue } & \text { Untrue } & \text { True } & \text { Totally True } & \text { Unsure }\end{array}$


7. Recreational sport allows me to gain acceptance from others in my new environment

$\begin{array}{lccc}\text { Totally } & \text { Somewhat } & \text { Somewhat } & \text { Totally True Unsure } \\ \text { Untrue } & \text { Untrue } & \text { True } & \end{array}$

8. Recreational sport provides me opportunities to socialize with others of the same cultural identity

$$
\begin{array}{lcccc}
\text { Totally } & \text { Somewhat } & \text { Somewhat } & \text { Totally True } & \text { Unsure } \\
\text { Untrue } & \text { Untrue } & \text { True } & &
\end{array}
$$

9. Participating in recreational sport allows me to enter into a new cultural environment

$\begin{array}{lcccc}\text { Totally } & \text { Somewhat } & \text { Somewhat } \\ \text { Untrue } & \text { Untrue } & \text { True } & \text { Totally True } & \text { Unsure }\end{array}$

10. Recreational sport allows me to network with individuals from diverse cultural backgrounds on campus

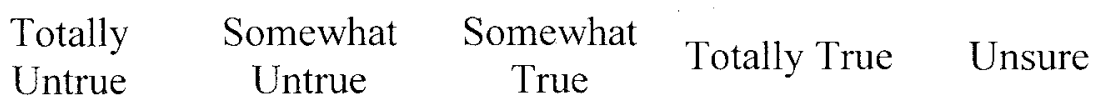

11. Participating in recreational sport on campus allows me to network with people from the same cultural background

$\begin{array}{lcccc}\text { Totally } & \text { Somewhat } & \text { Somewhat } & \text { Totally True } & \text { Unsure } \\ \text { Untrue } & \text { Untrue } & \text { True. } & & \end{array}$

12. Participating in recreational sport on campus helps my transition into a new environment by allowing me to engage in a familiar activity

$\begin{array}{lcccc}\text { Totally } & \text { Somewhat } & \text { Somewhat } & \text { Totally True } & \text { Unsure } \\ \text { Untrue } & \text { Untrue } & \text { True } & \end{array}$

13. Through recreational sport, I have socialized with individuals from different cultures on campus

$\begin{array}{lcccc}\text { Totally } & \text { Somewhat } & \text { Somewhat } & \text { Totally True } & \text { Unsure } \\ \text { Untrue } & \text { Untrue } & \text { True } & & \end{array}$


14. Through recreational sport, I have socialized on campus with individuals who share my cultural values/experiences

$$
\text { Totally Untrue } \begin{gathered}
\text { Somewhat } \\
\text { Untrue }
\end{gathered} \quad \begin{gathered}
\text { Somewhat } \\
\text { True }
\end{gathered} \text { Totally True Unsure }
$$

15. Recreational sport participation connects me with my cultural background

$$
\begin{array}{lcccc}
\text { Totally } & \text { Somewhat } & \text { Somewhat } & \text { Totally True } & \text { Unsure } \\
\text { Untrue } & \text { Untrue } & \text { True } & &
\end{array}
$$

16. Recreational sport participation allows me to become more connected to my new cultural environment

$\begin{array}{lcccc}\text { Totally } & \text { Somewhat } & \text { Somewhat } & \text { Totally True } & \text { Unsure } \\ \text { Untrue } & \text { Untrue } & \text { True } & & \end{array}$

17. I have met friends on campus of different nationalities through participating in recreational sport

$\begin{array}{lcccc}\text { Totally } & \text { Somewhat } & \text { Somewhat } & \text { Totally True } & \text { Unsure } \\ \text { Untrue } & \text { Untrue } & \text { True } & & \end{array}$

18. I have met friends on campus that have the same cultural background as my own through recreational sport

$\begin{array}{lcccc}\text { Totally } & \text { Somewhat } & \text { Somewhat } & \text { Totally True } & \text { Unsure } \\ \text { Untrue } & \text { Untrue } & \text { True } & & \end{array}$

19. Recreational sport allows me to express my cultural identity

$\begin{array}{lcccc}\text { Totally } & \text { Somewhat } & \text { Somewhat } \\ \text { Untrue } & \text { Untrue } & \text { True } & \text { Totally True } & \text { Unsure }\end{array}$

20. Participating in recreational sport makes me feel like I am part of the larger campus community

$\begin{array}{lcccc}\text { Totally } & \text { Somewhat } & \text { Somewhat } & \text { Totally True } & \text { Unsure } \\ \text { Untrue } & \text { Untrue } & \text { True } & & \end{array}$

21. Recreational sport allows me to publicly display pride in my culture

$\begin{array}{lccc}\text { Totally } & \text { Somewhat } & \text { Somewhat } & \text { Totally True } \\ \text { Untrue } & \text { Untrue } & \text { True } & \end{array}$


22. In order to participate in my favorite recreational sport on campus, I must socialize with students from different cultural backgrounds than my own

$\begin{array}{lcccc}\text { Totally } & \text { Somewhat } & \text { Somewhat } \\ \text { Untrue } & \text { Untrue } & \text { True } & \text { Totally True } & \text { Unsure }\end{array}$

23. Recreational sport allows me to meet others with the same nationality

$\begin{array}{lcccc}\text { Totally } & \text { Somewhat } & \text { Somewhat } & \text { Totally True } & \text { Unsure } \\ \text { Untrue } & \text { Untrue } & \text { True } & \end{array}$

24. Recreational sport provides me with an opportunity to adapt to the American cultural environment

$\begin{array}{lcccc}\text { Totally } & \text { Somewhat } & \text { Somewhat } & \text { Totally True } & \text { Unsure } \\ \text { Untrue } & \text { Untrue } & \text { True } & \end{array}$

25. What country are you from?

26. Which international area are you from?

(

a) Asia (China, Korea, Japan, etc.)

b) South Asia (India, Pakistan, Bangladesh)

c) Latin America (Brazil, Peru, Panama, Mexico, Dominican Republic, etc.)

d) Canada/United Kingdom/Australia/New Zealand

e) Africa (Nigeria, Kenya, Cameroon, etc.)

f) Europe (Germany, France, Spain, etc.)

g) Middle East (Syria, Saudi Arabia, Egypt, etc.)

27. How long have you been in the United States?
a) 1 year or less
b) more than 1 year and less than 2 years
r
c) between 2 and 3 years
*
d) more than 3 years 
28. What is your age?
a) $18-20$
b) $21-24$
c) $25-30$
(d) over 30

29. What is your gender?
ᄃ
a) male
b) female

30. Please provide a brief explanation of the way you define 'cultural identity':

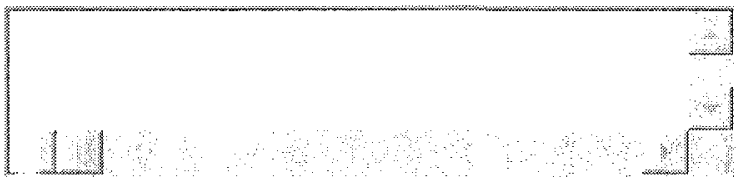

31. Please rank your top three recreational sports based on the FREQUENCY OF YOUR PARTICIPATION:

1) Tennis 2) Soccer 3) Badminton 4) Basketball

5)Baseball/Softball 6) Cricket 7) Volleyball

8) Golf 9)Rugby 10) Table Tennis 11) Martial Arts

12) Racquetball/Squash 12) American Football

13) Swimming 14) Cycling 15)Running/Track and Field

16) Ice/Field/Roller Hockey 17) Other:

First

Second

Third

32. How many times per month do you actively participate in recreational sport? 
33. Please rank your top three sports based on the FREQUENCY OF YOUR SPECTATORSHIP (attending live events, watching on television, etc.)

1) Tennis 2) Soccer 3) Badminton 4) Basketball

5)Baseball/Softball 6) Cricket 7) Volleyball

8) Golf 9)Rugby 10) Table Tennis 11) Martial Arts

12) Racquetball/Squash 12) American Football

13) Swimming 14) Cycling 15)Running/Track and Field

16) Ice/Field Hockey 17) Auto Racing 18) Boxing

19) Other:

First

Second

Third

34. Considering your sport spectatorship, with whom do you most frequently attend live sporting events?

a) individuals from the same cultural background

b) individuals from a different cultural background

35. Considering your sport media consumption (television, internet, newspaper, magazine), which do you most frequently use for entertainment and/or information?

a) domestic media (from the United States)

b) international media (from outside the United States)

c) domestic and international media equally

36. Please provide further details that you feel describe your experiences with sport on campus as it relates to socialization as well as opportunities to adjust to your new environment:

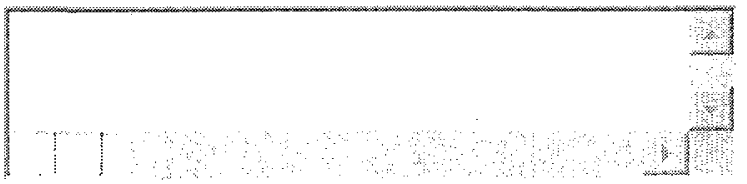

